\title{
Standards and Specifications for Ground Processing of Space Vehicles: from an Aviation-based Shuttle Project to Global Application
}

\author{
John Ingalls ${ }^{1}$ and John Cipolletti ${ }^{2}$ \\ United Space Alliance, LLC, NASA Kennedy Space Center, FL, 32899
}

\begin{abstract}
Proprietary or unique designs and operations are expected early in any industry's development, and often provide a competitive early market advantage. However, there comes a time when a product or industry requires standardization for the whole industry to advance...or survive. For the space industry, that time has come. Here, we will focus on standardization of ground processing for space vehicles and their ground systems. With the retirement of the Space Shuttle, and emergence of a new global space race, affordability and sustainability are more important now than ever. The growing commercialization of the space industry and current global economic environment are driving greater need for efficiencies to save time and money. More RLV's (Reusable Launch Vehicles) are being developed for the gains of reusability not achievable with traditional ELV's (Expendable Launch Vehicles). More crew/passenger vehicles are also being developed. All of this calls for more attention needed for ground processing-repeatedly before launch and after landing/recovery. RLV's should provide more efficiencies than ELV's, as long as MRO (Maintenance, Repair, and Overhaul) is well-planned-even for the unplanned problems. NASA's Space Shuttle is a primary example of an RLV which was supposed to thrive on reusability savings with efficient ground operations, but lessons learned show that costs were (and still are) much greater than expected. International standards and specifications can provide the commonality needed to simplify design and manufacturing as well as to improve safety, quality, maintenance, and operability. There are standards organizations engaged in the space industry, but ground processing is one of the areas least addressed. Challenges are encountered due to various factors often not considered during development. Multiple vehicle elements, sites, customers, and contractors pose various functional and integration difficulties. Resulting technical publication structures and methods are incongruent. Some processing products are still done on paper, some electronic, and many being converted inbetween. Business systems then are not fully compatible, and paper as well as electronic conversions are time-consuming and costly. NASA and its Shuttle contractors setup rules and systems to handle what has produced over $130 \mathrm{RLV}$ launches, but they have had many challenges. Attempts have been made to apply aviation industry specifications to make the Shuttle more efficient with its ground processing. One efficiency project example was to make a Shuttle Maintenance Manual (SMM) based on the commercial ATA (Air Transport Association of America) Spec 100 for technical publications. This industry standard, along with others, has been a foundation for efficient global MRO of commercial airlines for years. A modified version was also made for some military aircraft. The SMM project found many similarities in Spec 100 which apply to the Shuttle, and room for expansion for space systems/structures not in aircraft. The SMM project team met with the ATA and representatives from NASA's $\mathrm{X}-33$ and $\mathrm{X}-34$ programs to discuss collaboration on a national space standard based on Spec 100. A pilot project was enabled for a subset of Shuttle systems. Full implementation was not yet achieved, $X-33$ and $X-34$ were cancelled, and the Shuttles were then designated for retirement. Nonetheless, we can learn from this project how to expand this concept to all space vehicle products. Since then, ATA has joined with ASD (AeroSpace and Defence Industries Association of Europe) and AIA (Aerospace
\end{abstract}

\footnotetext{
${ }^{1}$ Senior Engineer, Launch \& Recovery Systems, Mail Stop USK-443, AIAA Senior Member.

${ }^{2}$ Chief Engineer-Ground Operations, Launch \& Recovery Systems, Mail Stop USK-022, AIAA Senior Member.
} 
Industries Association) to form a much-enhanced and expanded international specification: S1000D, International Specification for Technical Publications. It includes air, land, and sea vehicles, missiles, support equipment, ordnance, and communications. It is used by a growing number of countries for commercial and government products. Its modular design is supported by a Common Source Database (CSDB), and COTS (commercial off-the-shelf) software is available for production of IETP's (Interactive Electronic Technical Publications). A few space industry products in Europe have begun to apply S1000D already. Also, there are other related standards/specifications which have global implications. We have an opportunity to adapt S1000D and possibly other standards for use with space vehicles and ground systems. S1000D has plenty of flexibility to apply to any product needed. To successfully grow the viability of the space industry, all members, commercial and government, will need to engage cooperatively in developing and applying standards to move toward interoperability. If we leverage and combine the best existing space standards and specifications, develop new ones to address known gaps, and adapt the best applicable features from other industries, we can establish an infrastructure to not only accelerate current development, but also build longevity for a more cohesive international space community.

\section{Nomenclature}

\begin{tabular}{|l|l|l|l|}
\hline$A \& P$ & Airframe \& PowerPlant & $I S O$ & International Standards Organization \\
\hline$A I A$ & Aerospace Industries Association & $I S S$ & International Space Station \\
\hline$A S D$ & $\begin{array}{l}\text { AeroSpace and Defence Industries } \\
\text { Association of Europe }\end{array}$ & $I T$ & Information Technology \\
\hline$A T A$ & Air Transport Association & $L C N$ & LSAR Control Number \\
\hline$B R E X$ & Business Rules Exchange & $L S A / L S A R$ & Logistics Support Analysis/Record \\
\hline$C A L S$ & Computer Aided Logistics Support & $M R O$ & Maintenance, Repair and Overhaul \\
\hline$C O T S$ & Commercial-Off-the-Shelf & $O D F$ & Operations Data File \\
\hline$C S D B$ & Common Source Database & $O J T$ & On-the-Job Training \\
\hline$C S N$ & Catalog Sequence Number & $P L C S$ & Product LifeCycle Support \\
\hline$D R$ & Discrepancy Report & $P R$ & Problem Report \\
\hline$D o D$ & Department of Defense & $R C M$ & Reliability-Centered Maintenance \\
\hline$E E L V$ & Evolved Expendable Launch Vehicle & $R O I$ & Return on Investment \\
\hline$E L V$ & Expendable Launch Vehicle & $R L V$ & Reusable Launch Vehicle \\
\hline$E S A$ & European Space Agency & $S C$ & SubCommittee \\
\hline$E T$ & External Tank & $S G M L$ & Standard Generalized Markup Language \\
\hline$D M$ & Data Module & $S M M$ & $\begin{array}{l}\text { Shuttle Maintenance Manual, } \\
\text { and Structural Maintenance Manual }\end{array}$ \\
\hline$I E T M$ & $\begin{array}{l}\text { Interactive Electronic Technical } \\
\text { Manuals }\end{array}$ & $S N S$ & Standard Numbering System \\
\hline$I E T P$ & $\begin{array}{l}\text { Interactive Electronic Technical } \\
\text { Publication }\end{array}$ & $S R B$ & Solid Rocket Booster \\
\hline$I L S$ & Integrated Logistics Support & $S R M$ & Structural Repair Manual \\
\hline$I P$ & International Partners & $S T E P$ & $\begin{array}{l}\text { STandard for the Exchange of Product model } \\
\text { data }\end{array}$ \\
\hline$I P B$ & Illustrated Parts Breakdown & $T C$ & Technical Committee \\
\hline$I P P$ & Intranet-Provided Procedure & $T P S$ & Thermal Protection System \\
\hline$I P S$ & Integrated Product Support & $W G$ & Working Group \\
\hline$I P V$ & International Procedures Viewer & $X M L$ & Extensible Markup Language \\
\hline
\end{tabular}




\section{Introduction}

Technical information is an integral part of many jobs, and the space industry is no exception. Whether paper or electronic, we live off of our data. In fact, in this Information Age, it is more than just a necessity but it floods us to the point where it has created many challenges as how to create, use, and manage it. The book Information Overload examines the staggering statistics of time and money lost due to Information Overload, including:

- There are 78.6 million knowledge workers in the U.S. alone

- Information Overload cost the U.S. economy almost $\$ 1$ trillion in 2010

- A minimum of 28 billion hours is lost each year to Information Overload in the United States.

- 66 percent of knowledge workers feel they don't have enough time to get all of their work done

- 94 percent of those surveyed at some point have felt overwhelmed by information to the point of incapacitation.

- One major Fortune 500 company estimates that Information Overload impacts its bottom line to the tune of $\$ 1$ billion per year. ${ }^{1}$

For the space industry, technical data of many kinds drive work during the entire lifecycle. It's not just all about the vehicle design. Here are some types of functions which do not typically get in the limelight when talking about space programs. Even these types of hardware or functions may have technical data like 3D models, drawings, specifications, technical procedures, logistics, training, etc.:

Flight hardware

- Human space vehicles and stations even include toilets and kitchens.

Ground facilities and equipment

- A specification defines specific rocks required for a Shuttle crawler-transporter path to the pad.

Safety

- Using nickel cadmium batteries require a hazardous warning and protective equipment.

Mission data

- Micrometeorite/Orbital Debris (MMOD) impact damages are evaluated after each flight.

Mission operations

- Astronauts need medical procedures as well as sleep and eat schedules in-orbit.

Recovery operations

- Scuba divers must be trained and maintained to recover boosters or astronauts.

Training

- A swimming pool is required for mission training operations.

Ground processing

- IT systems require training, security, export control, design, planning, configuration management, technical support, and maintenance. (It sounds like flight hardware requirements!)

One efficient way to utilize our data is to move from paper to electronic information, but that is not enough! PDF files and other electronic document-oriented end products alone can just propagate paper. Electronic media may reduce cluttered or space-hogging desks or departments, but the new media can be cluttered, too, making it hard for users to find or use it. Many islands of information have been developed for particular groups, but they may or may not be well organized, and they are greatly limited when not connected to other systems. Interconnecting Information Technology (IT) systems can begin another level of efficiency gains. Many are doing this now. However, even then, it can be done inefficiently. The IT architecture or data interfaces may not be well organized. How user-friendly are the systems? To search, to browse, or to menu - that is a good question. Can the users find what they need in a timely manner? People have different learning styles, and data can have different structures-all which must be considered when designing IT business systems. Is the software easy to upgrade without disrupting your systems? Are your systems customized or Commercial-Off-the-Shelf (COTS)? Customization has its place, but the more it happens, the more it costs and impacts the lifecycle. 
What is needed is an overall plan for info structure and efficiency. "Research from Aberdeen Group's March 2010 'Benchmarking Content Reuse in Technical Communication' study found that... while reuse initiatives [to create more reusable content] offer significant improvements in efficiency, they can paradoxically increase the complexity and difficulty of content development processes. This means that as organizations build stores of reuseable content, they risk eroding the effectiveness of content developers. Instead, Best-in-Class take the extra step to focus on making content easier to reuse, which is what compounds the productivity of their content developers." ${ }^{2}$ This study confirms that technical publications content must be structured and well organized to optimize efficiency, and to avoid a reverse effect of information overload.

Lastly, how many "catch-all" plans are available to handle all of the needs during the lifecycle? Which ones are appropriate for a product, company, or industry? The space industry often views itself as unique, thus not always seeking or finding solutions in other industries or government sources. It is unique for many design and performance aspects, but ground processing has many tools and methods available in industry which could be applied from manufacturing to retirement. Turning wrenches is not very different, if at all, anywhere you go. Industry standards have been developed over the years, as best practices have been captured. Standards can normalize and optimize processes and procedures. See the example of the estimated effects of standardization in the figure below.

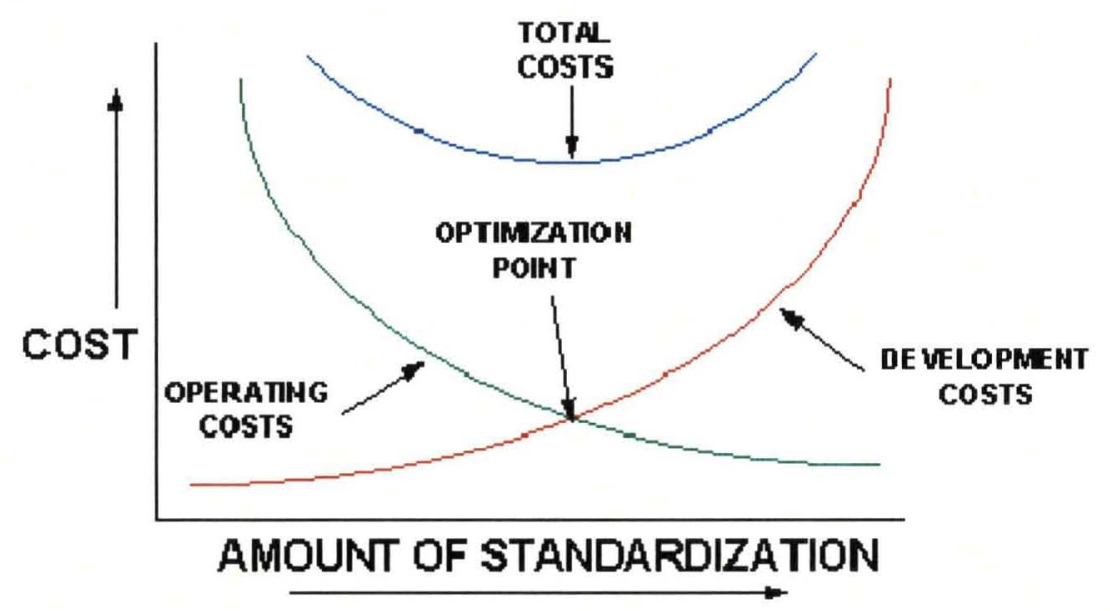

Figure 1. Estimated Standardization Effects Example ${ }^{3}$

Proprietary or unique designs and operations are expected early in any industry's development, and often provide a competitive early market advantage. However, there comes a time when a product or industry requires standardization for the whole industry to advance...or survive. For the space industry, that time has come. Here, we will focus on standardization of ground processing for space vehicles and their ground systems.

\section{Need for Standardization in the Space Industry}

With the retirement of the Space Shuttle, and emergence of a new global space race, affordability and sustainability are more important now than ever. The growing commercialization of the space industry and current global economic environment are driving greater need for efficiencies to save time and money. More RLVs (Reusable Launch Vehicles) are being developed for the gains of reusability not achievable with traditional ELVs (Expendable Launch Vehicles). More crew/passenger vehicles are also being developed.

All of this calls for more attention needed for ground processing-repeatedly before launch and after landing/recovery. RLVs should provide more efficiencies than ELVs, as long as MRO (Maintenance, Repair, and Overhaul) is well-planned - even for the unplanned problems. NASA's Space Shuttle is a primary example of an RLV which was supposed to thrive on reusability savings with efficient ground operations, but lessons learned show that costs were much greater than expected. 
International standards and specifications can provide the commonality needed to simplify design and manufacturing as well as to improve safety, quality, maintenance, and operability. When standards are chosen strategically and applied effectively, they can help enable efficiencies which lower costs. They represent proven best practices, known methods, known worker skills, and COTS software, as well as improved safety and quality.

\section{A. Industry Standards for Space}

Various organizations produce standards and specifications. The space industry has a few, such as National Aeronautics and Space Administration (NASA), European Cooperation for Space Standardization (ECSS), Consultative Committee for Space Data Systems (CCSDS), etc. There are standards organizations that are not exclusive to the space industry which include some standards for space. One example is the International Standards Organization (ISO).

Many of the over 200 ISO Technical Committee (TC) areas apply to aerospace. Each Technical Committee is divided into SubCommittees (SC) for major functional areas, and the subcommittees are further parsed into Working Groups (WG) with very specific focus. TC20 is Aircraft and Space Vehicles, which includes two SCs for space-SC13 Space Data and Information Transfer Systems, and SC14 Space Systems and Operations.

Standardization of space hardware design is important and increasingly needed. It provides many advantages. One good example is the Evolved Expendable Launch Vehicle (EELV). The EELV Standard Interface Specification (SIS) produced modular improvements like standard payload interfaces, common booster cores, and standard launch pad interfaces, allowing multiple vehicle configurations for various payload customers. Another is the Range Standardization and Automation (RSA), referred to as Spacelift Range System (SLRS) programs, addresses range equipment upgrades and standardization that will modernize and improve capabilities at U.S. Eastern and Western Ranges, while attempting to reduce operations and maintenance costs. ${ }^{4}$

However, with all Standards Development Organizations (SDO), ground processing is one of the areas least addressed. By ground processing, that could include assembly/integration, test and checkout, launch operations, maintenance and repair, supporting infrastructure systems, etc. Any of these could apply to a launch vehicle, payload/cargo, space station/habitat, launch pad, processing facility, or support equipment. Ground processing is typically covered by what the industry calls Integrated Logistics Support (ILS) or Integrated Product Support (IPS). ${ }^{5}$ The EELV requirements include a call to standardize infrastructure and processes in addition to design. The RSA includes an aim to normalize logistics support, which includes standardization of procedures. Yet, are such efforts using published industry standards or making their own internal tasks standardized, as in fixed or repeatable?

\section{B. The Need for Standards in Ground Processing}

Let us look at the need for effective and efficient technical data. According to "The Hidden Costs of Information Work," a 2006 IDC study of information/knowledge workers, it revealed that ${ }^{6}$ :

- They spend 48 percent of time searching $(9.5 \mathrm{hrs} / \mathrm{wk}) \&$ analyzing $(9.6 \mathrm{hrs} / \mathrm{wk})$ information.

- They waste $3.5 \mathrm{hrs} / \mathrm{wk}$ in unproductive searches (information not found).

- They waste $3 \mathrm{hrs} / \mathrm{wk}$ recreating content that already exists.

- Not finding the information needed costs an organization employing 1,000 knowledge workers about US\$5.3 million per year.

"Knowledge workers" is a term typically for those who use knowledge to analyze, design, make decisions, or do some action based upon knowledge they have or gather. It has been used often for engineers, scientists, researchers, coders, etc, but it is also recognized as applicable to anyone needing to seek or use knowledge for their tasks. That said, the statistics above could apply to the space industry for not only engineers and designers, but also mechanics, inspectors, planners, etc. If space vehicles were so mundane that everything was a routine, mindless task, then a knowledge worker would not be needed. However, a great amount of knowledge and agility is required when working on a space program.

Technical data is everywhere, but it is not always easy to find, or even know that it exists. Information is sometimes recreated or even missed, causing a more costly resulting action. Multiple contractors, sites, vehicle elements, and configurations can complicate the ability to find or interpret data sources. The EELV requirements document stated in 1998 that one of the reasons that the Expendable Launch Vehicle (ELV) launch systems at the time were cost ineffective was due to lack of standardization of facilities, processes, vehicles, procedures, and supporting infrastructure, making each mission a unique event. ${ }^{3}$

The organization of technical data itself can be inefficient. Each contractor may structure his product breakdown a different way, shown in drawings, specifications, logistics, various databases, or technical publications. Each data 
set may have a different IT business system to access such data, and these may not be interconnected. The Space Shuttle and the Ares I-X test rocket are examples that used various manufacturers and business systems, making it difficult to find all data efficiently. The now-retired Shuttle had so much old legacy data that it was too difficult to synchronize everything by the time the retirement decision came. Ares I-X began with that experience under its belt, and with modern IT tools, but technical data for each contractor for each major element was still structured differently. United Space Alliance (USA) had the task of integrating all together and developed an IT architecture to make various data sets visible together under standard applications. Had the data been synchronized upfront, it would have been a much easier feat.

Creation, use, and management of technical data are vital—even more so with these challenges.

\section{Shuttle Maintenance Manual (SMM) Project}

\section{A. Ground Maintenance of NASA's Shuttles}

One of the enhancement efforts during the Space Shuttle years was to reorganize some of the technical data for more efficient ground processing. The focus was technical publications - specifically work procedures and reference manuals. Shuttle processing had a variety of work procedure types, all organized differently. All were authored by engineers, with management by different documentation departments. Thousands of procedures were routine, but thousands after each flight were unplanned. Engineers were responsible to write disposition for approximately 80 to 95 percent of all nonconformances. The data sources needed for the engineers to author planned or unplanned procedures were numerous and scattered (see Figure 2 below). Technicians and quality inspectors also had to research technical data to identify nonconformances. They also had authority to write disposition without engineering on a small percentage of unplanned nonconformances, and thus they needed these data sources, but many of those sources were not known or available to them. They often could not find all data needed, so they frequently contacted engineering for assistance.

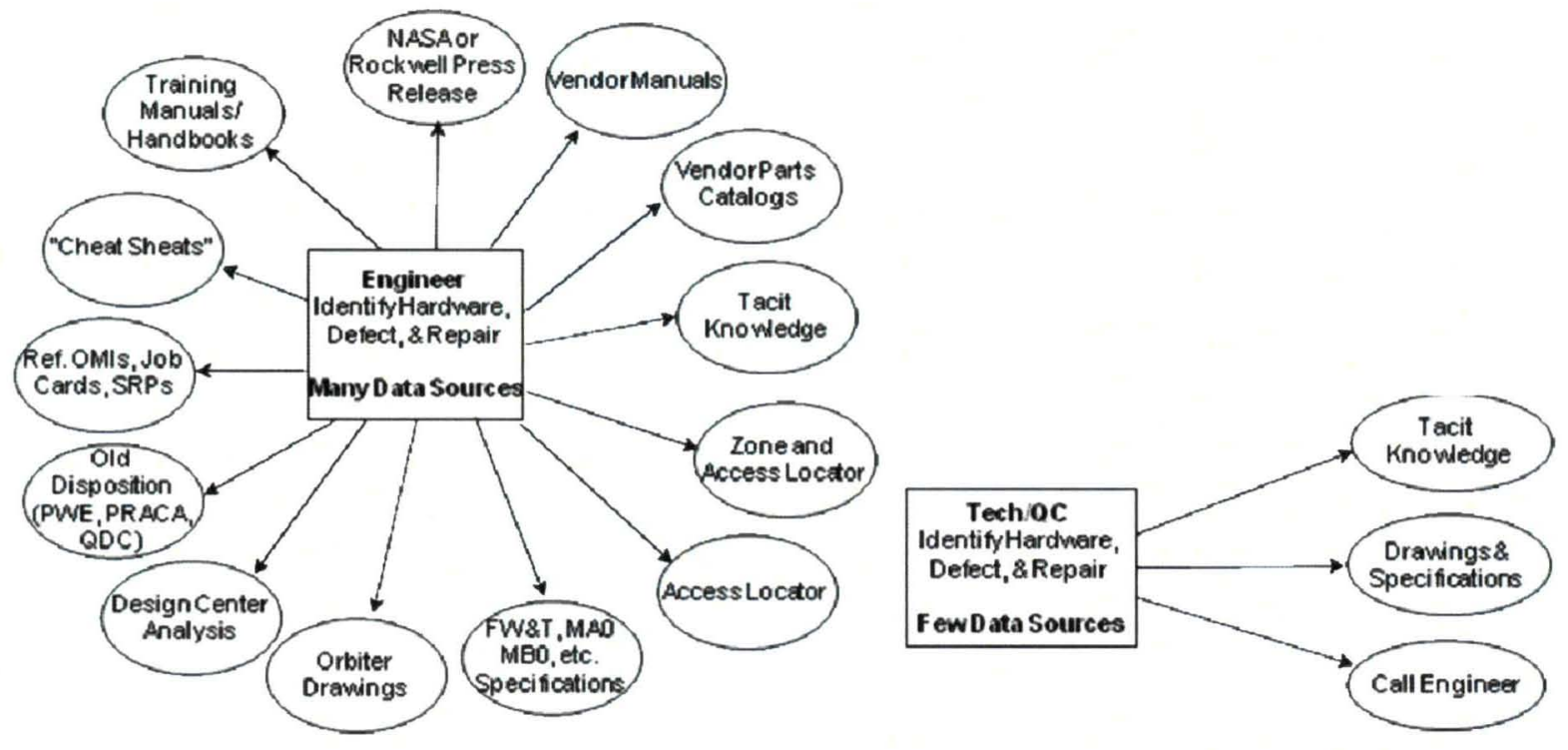

Figure 2. Various Data Sources for Shuttle Nonconformance Resolution

Technical publications (a.k.a. "Tech Pubs") in the industry typically include comprehensive technical data with reference overviews, Illustrated Parts Breakdowns (IPB), defect limits, troubleshooting, and finally the actual work steps. These were often produced as maintenance manuals, repair manuals, fault isolation manuals, etc., often as an Interactive Electronic Technical Manual (IETM).

Shuttle had few reference manuals, essentially no IPBs, and scattered sources to find a small portion of hardware with defect limits or troubleshooting methods. All such data was in various places, or else merely tacit knowledge. What remained were tech pubs of just work procedures. At the time, most procedures had few illustrations. To resolve the many nonconformances after each flight, unique disposition usually had to be written due to few 
preapproved standard procedures. There were some standard rework procedures, where inspection, cleaning, or part replacement was performed. There were some standard repair procedures, where final resolution allowed a permanent fix that could not restore to drawing/specification condition. The vast majority of preapproved procedures at this time were for routine maintenance, test, integration, and launch operations. The numbering scheme was unique for each procedure type, making it more difficult for all personnel to find which was needed at any given time - for unplanned standard procedures or for routine procedures. NASA had a high-level Shuttle subsystem numbering scheme, but it was not completely consistent in itself, nor was it consistently applied to ground processing.

There was one exception - the Orbiter's Thermal Protection System (TPS), which discovered long before this that the fragile heatshield tiles sustained numerous damages during each flight. Over the years, by sheer volume of nonconformances and time-consuming maintenance needed, they developed a system of defect limits and preapproved procedures to handle the majority of their numerous nonconformances. Technicians wrote disposition for a large portion of TPS nonconformances, (as opposed to non-TPS). That TPS system was one of the better streamlines available, but the maintenance was still consuming.

\section{B. Aviation-Based Efficiency Application Efforts}

In 1997, a NASA and USA team formed an idea to create a Structural Repair Manual (SRM) for the Orbiter, similar to those used by the military and commercial aircraft industry. Rather than merely gathering all existing applicable technical data for Orbiter Structures, more building blocks were desired to enable a more substantial manual:

- Performed trend analysis to identify the highest occurrence of nonconformance types and hardware

- Requested from the Boeing design representatives more defect limits on more hardware

- Created more standard rework procedures

- Created more standard repair procedures

A team was formed with USA, NASA, and Boeing representatives at KSC, JSC, and Boeing's California site, from engineering, shop, quality, design, and reliability. For the kick-off, a tech pubs expert from Boeing's commercial airplane division in Seattle came to demonstrate their system of maintenance and repair manuals. The team compared those manuals with military manuals, as well as the handful of vendor manuals made for small Shuttle systems or hardware. Each had different numbering schemes, document structures, page formats, and textual and graphics rules and guidelines. The team performed an objective decision analysis and agreed to use the commercial Spec 100 from the Air Transport Association (ATA), titled Specification for Manufacturers' Technical Data.

As the project progressed, it was seen that applicability should include more than just repair, but also common maintenance rework and inspection. The project was renamed the Structural Maintenance Manual (SMM). Later still, it was expanded beyond just Structures, seen as potentially applicable to all systems and hardware for the Orbiter, External Tank (ET), and Solid Rocket Boosters (SRB). It was then renamed the Shuttle Maintenance Manual (SMM). The overall goal was to gather all work procedure types into one system integrated with related technical data. The intended product would provide the following improvements (plus more in a future revision):

- Reorganize documents by product structure based on hardware system/subsystem

- Renumber documents with a common, intelligent numbering scheme

- Combined technical reference materials, defect limits, and work procedures for each subsystem

- Web-based access and interaction with drill-down links (by the numbered product structure), see Fig. 5

- Setup for interoperability with other business systems, using efficiencies via the new product structure

- Inclusion of multimedia for reference, training, or procedural aide

- Increased illustration usage along with reduction of text to only the necessary levels for a skill-based workforce

- Organize all safety warnings into one place and have procedures point to them rather than repeat each text

- Separate sheets to verify/buy-off work steps (-separate process rules from technical content; less archives)

- Common page format (-Shuttle had mostly reached this goal by this time, via another effort.)

The numbering scheme was a key to start with, since it represented the product structure of the hardware and systems. NASA's numbering scheme was structured by hardware/systems, but not sufficient. The ATA scheme was advantageous since many in USA had Airframe \& PowerPlant (A\&P) licenses or aircraft industry background, so they were familiar with it. ATA also includes generic processes and requirements in their scheme. However, ATA's 
scheme did not have SRB's, an ET, fuel cells, a TPS heatshield, etc. Its systems/chapters were very similar to those of Shuttle, but modifications were needed. NASA's X-33 and X-34 space vehicles were in development at the time, so the SMM team met with representatives from them and the ATA to discuss a unified scheme for a national space standard.

\section{Advantages of ATA Specifications}

The ATA of America is a trade organization that has been benefiting commercial airlines since its inception in 1936. Among many other things, the ATA serves as a focal point for industry efforts to standardize practices and enhance the efficiency of the air transport system. They have an entire suite of specifications for most aspects of airline maintenance and flight operations--from scheduled maintenance to reliability to materiel management.

For tech pubs, Spec 100 is the foundation to organize technical data content and format. Its original versions addressed use of the content as digital data. The digital data structure was separated in 1994 into ATA Spec 2100, which used Standard Generalized Markup Language (SGML) as the structured authoring method. This provides control of digital display and print format, plus it enables interoperability with other systems via data exchange controls. In 2000, during the SMM project, Spec 100 and 2100 combined into iSpec 2200, the current version today, titled "Information Standards for Aviation Maintenance."

Typically, airline manufacturers would create ATA manual sets and deliver them with their aircraft to customers. The airline customer technician would use the manuals to perform routine or unplanned maintenance. As long as the maintenance was in the manuals, and within its limits, an engineer was not required. Because the manuals were so thorough, very few situations required an engineer-roughly 1 to 10 percent. Even when an engineer was required, their disposition often was unique approval to apply a manual's procedure outside of its limits. Now that the digital age is in swing, most airlines should have electronic manual sets instead of the prior paper versions.

The organizational intelligence, consistent format and content, electronic media, and interoperability have been a beacon of efficiency for all industries. Because of this, the ATA system has been used by many international carriers/locations as well. One specification used to accommodate international usage is the Simplified Technical English specification ASD-STE100. Training for the industry standard A\&P license includes ATA manual usage.

\section{Pilot Program}

The SMM set out to make what would be a huge culture change in Space Shuttle ground operations. Even average changes were not easy to get approved. This change to an atmosphere full of legacy systems and personnel accustomed to them was meeting many questions and resistance.

A pilot program was begun to provide objective metrics and subjective evaluation of the merits and risks of changing all Shuttle tech pubs. The pilot was established for only Orbiter Structures, only in the horizontal processing facilities, and only for the shops responsible for the Aft section. Preapproved work procedures allowed were limited to rework, inspection/troubleshooting, and repair, to be called out in disposition to resolve the two nonconformance types: Problem Reports (PRs) and Discrepancy Reports (DRs). Shuttle rules direct dispositions to be written for PRs by engineers and for DRs by technicians.

One goal of the pilot was to measure if processing time would be reduced by implementing the SMM instead of legacy procedures. The theory was that time savings would be seen in various facets, so a form was setup to measure time spent for each task which could be performed by the various personnel who would touch a PR or DR, using parameters to record who performed each action, what type of activity they performed, and how long.

The desired results by using the SMM versus legacy documents were to show:

1) Reduced time identifying problems and researching by all personnel.

- REASON: having needed technical data in a logically-found location via a web-driven drill-down via intelligently numbered subsystem structure, defect limits visible and more of them, troubleshooting charts available, prominent reference illustrations for location and detail, and additional technical reference materials (text and multimedia)

2) Reduced disposition time by engineers and technicians, and confidence to transfer more PRs to DRs.

- REASON: finding the right procedure quicker with improved identification and research data available (see above), and having more preapproved procedures

3) Slightly reduced document assembly time and scheduling time.

- REASON: intelligent numbering/structure and more preapproved procedures

4) Reduced hands-on work time by technicians and inspectors.

- REASON: more easily understood procedures with simpler text, more graphics, and improved identification and research data available (-see above) 
Metrics were taken with legacy and with Pilot SMM procedures. Unfortunately, it was difficult obtaining sufficient and consistent metric data to enable a solid study. Shuttle workers are very focused on their tasks, aiming to complete their work quickly while paying attention to details for quality and safety. Though all were excited about SMM demonstrations given before the Pilot, metrics were enough of a burden that the results were less than optimal. Even so, the metrics showed even, positive trends.

The Pre-SMM data using legacy procedures was done on PRs and a few DRs. The SMM Pilot data was all DR work with the online SMM web materials and procedures. The overall time savings average per PR/DR was $30.3 \%$ using the SMM Pilot. In the first figure below, the distribution of the time spent on each PR/DR indicates that less engineering time was needed, giving confidence (desired result \#2) to transfer more PRs to DR level, so that technicians could disposition more nonconformances without engineering than before.

\section{Pre-SMM Data Percent Time by Org}

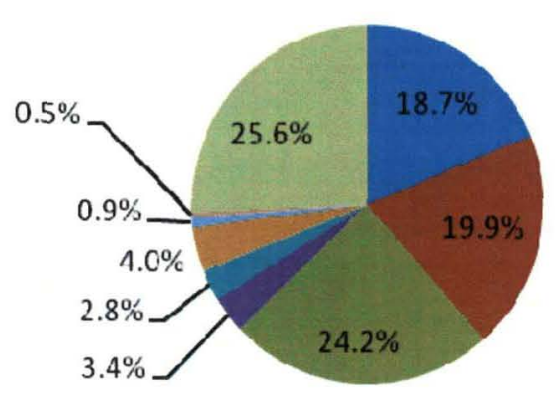

\section{SMM Pilot Data Percent Time by Org}

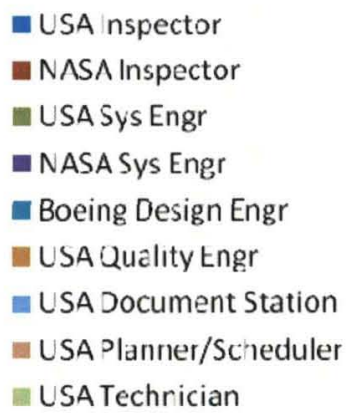

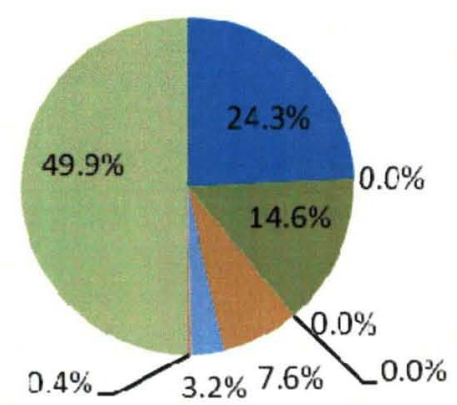

Figure 3. SMM Pilot Time Distribution by Role/Organization Working PRs/DRs

The next figure shows distribution of time spent on each processing activity. Results indicated that desired result \#1 was accomplished, which also revealed the majority of the resolution process was spent by hands-on technician time, as it should be. The raw data also showed less average hands-on time spent by technicians and inspectors, accomplishing desired result \#4. Only technician disposition time was increased, which is understandable since responsibility shifted from an engineering PR to a technician DR. This aspect of desired result \#2 was not met due to inaccurate assessment. Raw data also showed desired result \#3 accomplished.

\section{Pre-SMM Data \\ Percent Time by Activity}

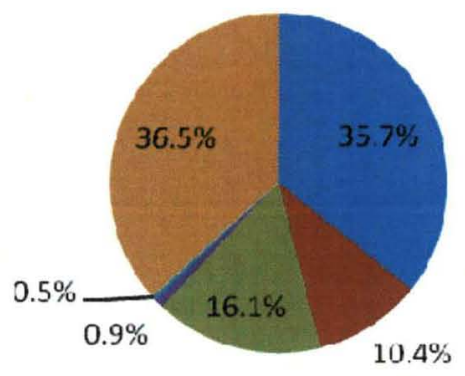

\section{SMM Pilot Data Percent Time by Activity}

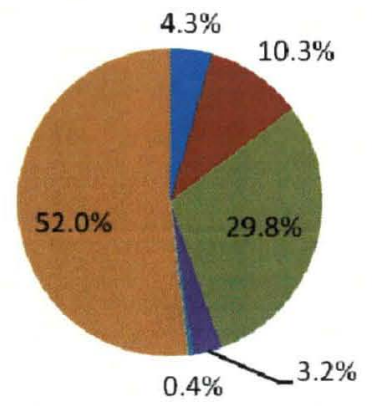

Figure 4. SMM Pilot Time Distribution by Action Taken on PRs/DRs 


\section{E. Current Project Status}

Pilot results were presented, but the SMM project never got full acceptance to proceed further. It was subjected to various doubts and uneasiness at upper level reviews before and after the pilot. It was still difficult to justify conversion to such a large change after 20 years of legacy operation. Project leadership, membership, and management supporters also changed during the pilot. There was a wave of other big enhancement projects ongoing at the same time, some which bore fruit, and some which faded away. A similar effort to renumber all procedures (using a customized NASA-based scheme) had lost support just a few years earlier. Also, a similar effort to use SGML structured authoring had just been replaced a few years earlier with a structured Microsoft Word-based system. External factors also stifled the potential for progress. X-33 and X-34 were cancelled. The Space Shuttles were then designated for retirement, making the value of conversion impractical.

However, some benefits were produced as a result of the SMM effort. A spinoff system was produced called Intranet-Provided Procedures (IPP). The need for preapproved maintenance rework procedures was seen. All engineering systems created many such small procedures, previously only authored uniquely or copy-pasted text from unofficial reusable templates kept in various places. The IPP system was enabled via the Intranet. Efforts were made to simplify text and graphics, and standardize format. Technicians could author more dispositions on DRs with more applicable scenarios existing.

A spinoff was that the Safety organization organized and numbered their warnings. Also, these were eventually integrated with the legacy disposition system, standardizing warnings and making them easy to insert into a structured disposition.

The SMM continues to exist, but as a technical reference system instead of official system for procedures. See Figure 5. It is essentially an IETM. Since the pilot:

- Instead of renumbering all procedures, the SMM provides an intelligently-layered drill-down menu to enable ease of finding the legacy procedure needed. The SMM website merely points to the legacy procedures, dynamically linked to the latest version from the legacy source.

- The SMM was expanded to more document types, including technical reference files, maintenance requirements documents, IPP's, reusable disposition templates (based on SMART, another enhancement project), legacy preapproved procedures (3 types), a graphics library, and even links to disposition sets PRs, DRs, and another document type used for modifications and special tests. Any of these documents could be any file type-PDF, Word, Excel, PowerPoint, video, image, etc.

- Training materials were included in the reference files section, which enabled a system for on-the-job training (OJT), enhanced by the other data for each subsystem.

- The SMM demonstrates a powerful and unique IT arrangement and functionality. It uses a Cold Fusion web front, with queries passing through Web Services, to retrieve content files from a Documentum repository. This was a first for USA, and we had not heard of others outside doing this, at the time. Anything located in Documentum is able to be displayed on the SMM web. Unique files can be stored in the SMM location, or Documentum shortcut links can point to source files located in their official folders. Any files or shortcuts placed in the SMM folders will instantly, dynamically display on the website without curator interaction or coding (as long as a specific property is enabled by the author).

- Though the main intent is to use the SMM as a technical manual based on a hardware/system product structure, a side structure was added, organized by engineering group. It is setup for joint file access for USA, NASA, and local design representatives for certain files, as well as other USA data and processing files.

- The SMM is still used some for Shuttle transition and retirement now.

The SMM has become a model for tech pubs to be used for future space programs, being used to evaluate future requirements and standards. 


\begin{tabular}{|l} 
Shuttle Maintenance ManUal (SMM) \\
Unted spanc Amlance
\end{tabular}

Figure 5. SMM Web Application Example

\section{Significant Optimization of Technical Publications for Space}

In "Technical Communications as a Profit Center", the Aberdeen Group studied 165 companies in 2009 to determine how strategic is product documentation or the technical communications department that produces it. The Best-in-Class exhibited the following characteristics:

- $65 \%$ increase reuse of content across technical communications

- $100 \%$ use graphic/image editors, and $43 \%$ use rich media/e-learning editors

- $46 \%$ more likely to leverage structured authoring editors

- $86 \%$ more likely to use CMS [content management system] to manage relationships between content components

- $38 \%$ and $61 \%$ more likely than industry average and laggard performers respectively to automatically assemble content based on product configuration

- $100 \%$ more likely to measure performance of technical communications with formal metrics ${ }^{7}$

\section{A. S1000D Enhancement and Expansion of ATA Specification}

ATA iSpec 2200 addresses each of these Best-in-Class features for commercial airlines. Meanwhile, the ATA model was copied as the foundation of a new specification in Europe which now does all of these things and moreS1000D, "International Specification for Technical Publications Utilizing a Common Source Database (CSDB)". It is now a global specification with international collaboration and use. It is designed for and represented by users of air, land, and sea vehicles, missiles, communications, and support and training equipment. One of those managing representation organizations is the ATA.

ATA has joined with the AeroSpace and Defence Industries Association of Europe (ASD) and the Aerospace Industries Association (AIA) to form this much-enhanced and expanded international specification. It is used by a growing number of countries for commercial, civil, and government products. Many customers have been mandating S1000D in their contracts, including many U.S. Department of Defense (DoD) products. Some have found enough advantages that they are converting legacy systems to S1000D. 
Examples of industry products using S1000D:

- Boeing 787 airplane

- JSF F-35 Lightning II airplane

- F-18 404 engines

- F-117A aircraft

- Global Hawk unmanned vehicle

- AMRAAM missile

- NLOS missile
- CH148 Cyclone helicopter

- CH146 Griffon helicopter

- VH71 Presidential Helicopter

- FIREFINDER radar

- Naval Sea Systems Littoral Combat Ship Mission Module Program

- EMALS/AAG systems on CVN78 ship

\section{B. Powerful Features of S1000D}

S1000D provides features which are leaps and bounds beyond traditional tech pubs of the past. It is more than converting paper to electronic files with a smart document number. The specification defines a system for the creation, storage, management and delivery of technical data. It is not just Extensible Markup Language (XML), Schemas, and IETMs, but it is a lifecycle process for technical information. Also, S1000D is an open standard and provides a non-proprietary XML schema. Below are key features of an S1000D system. ${ }^{8}$

\section{Based on International Standards}

- ISO standards are used for codes, information formats, etc. W3C web-related standards are used (XML, etc.). ATA standards for are used for graphics.

Electronic Publications (IETM/IETP)

- End user deliverables of S1000D are the IETMs, which S1000D calls IETPs (Interactive Electronic Technical Publications). Users access needed technical data via an electronic viewer, whether for training, research, or work procedures. The end products they will see are Publication Modules (PM), which compile all data into a presentable package as maintenance manuals, IPBs, training manuals, etc.

Standard Numbering System (SNS) Product Structure

- The SNS defines the product structure based on a hardware/system/subsystem drill-down. This alphanumeric coding standardizes the arrangement of technical information, becoming the core for the overall technical data usage and interoperability. Some predefined SNSs are maintained in the specification based on industry best practices, but a unique SNS is allowed if truly needed.

Modularity for Reusability/Repurposing

- Data Modules (DM) are at the core of S1000D. Technical data is created in small enough units of information that DMs can be applied in multiple ways. The same DM might be reused, or repurposed, in 3 different IETPs, like a maintenance manual, a training manual, and an IPB, for example.

Common Source Database (CSDB)

- A CSDB is a virtual store for the objects produced by a project: DMs, multimedia objects, publication modules, administrative objects, etc.

Illustrations, Multimedia, and CAD

- Illustrations and multimedia are allowed in multiple file formats. CGM is used as the standard for interactive graphic hotspots. $\mathrm{CAD}$ is not well defined in the specification yet, but it will still work with an S1000D system. Many COTS software vendors have configured their IETP viewers with 3D model viewing capability, beyond the specification. Meanwhile, there is an S1000D working group moving to incorporate Model-Based Enterprise capabilities into the specification.

Applicability - Structured Configuration Varieties

- The "Applicability" feature allows end product "custom" appearance to any configuration/situation. Using the EELV requirement mentioned earlier, with past ELVs having a unique configuration each time, S1000D can enable only DMs applicable to a certain vehicle configuration, so users do not need a completely new tech pub each time, and the configuration management is built-in. This same concept can be applied to different DMs or tagged data options needed for varying locations, different technicians/skill levels, weather conditions, etc. The IETP user only sees what applies.

\section{Business Rules Exchange (BREX)}

- BREX is a method to formally specify and exchange business rules between parties with interests in the CSDB content. S1000D is rigid enough to provide efficient structure, but flexible enough to allow certain business requirements to be applied if needed. 


\section{External Interoperability}

- In addition to reusability and applicability features within S1000D, collaborative production and use of information is enabled with systems outside S1000D. Standard interfaces with design, Logistics Support Analysis/Record (LSA/LSAR), and provisioning/materiel management systems can pass needed data to S1000D, enabling wider reusability of technical data as well as improving configuration management. Unique, external applications can also exchange data via a standard S1000D interface.

Aside from efficiencies and interoperability is the manner in which S1000D can improve the safety of the operating and maintenance environment by making information available across a dataset or enterprise. Semantic XML in general allows for data mining which is helpful in locating critical information in technical data for realtime updates to configurations. The entire dataset can be searched and updated to provide current information to the user.

One of the means by which S1000D can provide many of its features is the use of XML - not only for structured authoring, but for data exchange. SGML was the standard in the past, used by ATA and S1000D, but XML is the best modern standard. XML content management solutions are built on three fundamental principles to help automate processes:

1) Manage content components, not documents. This localizes changes, and users can share and reuse common components across multiple products and deliverables. As a result, the time and cost associated with creating and delivering highly dynamic content to end users is dramatically reduced.

2) Use consistent XML data versus unstructured data. XML supports the ability to tag content. Through the use of tags, a user can get the specific content they need, when they need it - whether it's a whole document, multiple documents, or even one paragraph.

3) Support multiple channels of delivery - including print, Web, and electronic output. When packaging the content for delivery via multiple channels, there are numerous considerations on the delivery side to consider during implementation, including: who can see what data; configuring the right data for the right person at the right time; presenting the content in the appropriate language; and supporting advanced search and navigation.

"The return on investment (ROI) realized by moving to XML-based content creation, management, and delivery platforms has been well proven. Historically, however, the cost and time associated with developing and implementing an XML-based process have deterred many organizations that might otherwise have considered such an approach. Now emerging, more prescriptive standards such as DITA and S1000D, in combination with intelligent delivery platforms, can make use of this enriched data, ultimately changing the way organizations large and small create and deliver information." 9

Both standards are for topic-based systems which take advantage of reusable, structured content. DITA is generally more suited for software technical documentation. S1000D is generally more suited for complex vehicles, ground equipment, or systems. For the space industry in general, we recommend S1000D.

\section{Case Study: Benefits of S1000D Use}

One customer of a U.S. military product listed the following realized benefits of using S1000D:

- Decreased Lifecycle Support Costs

$>$ Streamlined change management and multi-format delivery process

$>$ Increased revision efficiency

$>$ More time for data review leads to reduced data errors

$>$ Decreased Technical Orders (TOs)

$>$ Contracting Data Modules (DMs), not publications

$>$ Quality $\uparrow$ Costs $\downarrow$

- ROI Factors

$>$ Average cost savings \% using S1000D for the program - "High Teens"\%

$>$ Data Reuse - achieved up to $70 \%$

$>$ Realized up to $50 \%$ cost savings producing manuals

$>$ Realized opportunities to manage common data $-10 \%$ same in all books

$>$ Realized added benefits of Applicability

$>$ Reduces numbers of books authored, edited, maintained, but retain ability to deliver all configurations required

$>$ Increased output consistency 
- Other Benefits of S1000D

$>$ Increased contractor proficiency

$>$ Increased competition / reduced government costs!

$>$ Common naming conventions

$>$ Streamlined data exchange between vendors, and joint services

$>$ Use of business rules lead to:

$>$ Improved validation and increased data quality

$>$ Better technical data acquisition control

\section{Applicability to All Space Products}

The SMM project and the more extensive S1000D show us that an industry standard for technical publications can and should be applied to all space vehicle products: launch vehicles, payload/cargo, spacecraft, support equipment, facilities, space stations/habitats, lunar landers, and recovery ships.

A few space industry products in Europe have begun to apply S1000D already. Germany's DLR uses it for their Galileo satellite ground station. It is used in Italy for a space telescope. In the U.S., the only known case is the recent development of S1000D for the Eastern and Western SpaceLift Range System.

We have an opportunity to adopt S1000D and possibly other S-series standards for use in the space industry now. An effort has been in work to begin a Space Working Group within the S1000D organization. Representatives would have opportunity to submit change requests to the specification, as well as gain a network of resources to support any S1000D project.

The ideal time to start S1000D usage is at the beginning of new product development. The global space industry is going through such a time, with many new launch vehicles, spacecraft, space stations/habitats in design, development, or test. One of the first steps is to organize a product structure for the SNS. The S1000D specification publishes maintained SNSs for various product types - just not for space (yet). However, those can be utilized as baselines or examples. In other cases, a new SNS could be formed, using some of the same logic of existing SNSs. For example:

- ELVs - compare the Missile SNS or Air SNS

- Manned Spacecraft - compare Air SNS, and the unofficial Shuttle SNS used in the SMM

- Recovery Ships - compare Sea SNS

- Support and Training Equipment - use SNS of the same name

- Space Station/Habitat - create a new standard SNS, but compare Air, Land, and Sea SNSs

\section{E. International Space Station's (ISS) Similar IETM for Astronauts}

The ISS assembly was completed this year. Astronauts now reside there for lengthy stays like 6 months before rotating back to Earth. This massive structure in orbit is more than a habitat but is an international scientific laboratory, as well as a space vehicle which is constantly travelling. Many technical publications are required to not only operate this marvel, but also to maintain and resupply it. Also, tech pubs are even needed for human living situations for the astronauts - medical, food, exercise, etc. ISS tech pubs are used by astronauts on-orbit, astronaut ground training, and ground controllers.

The ISS currently uses an efficient technical publication system that has many features similar to and compatible with S1000D. United Space Alliance (USA) developed this system for the team of International Partners (IP). After migrating years ago from the PDF-based Manual Procedures Viewer (MPV), the ISS now uses the International Procedures Viewer (IPV). See the figure below. 


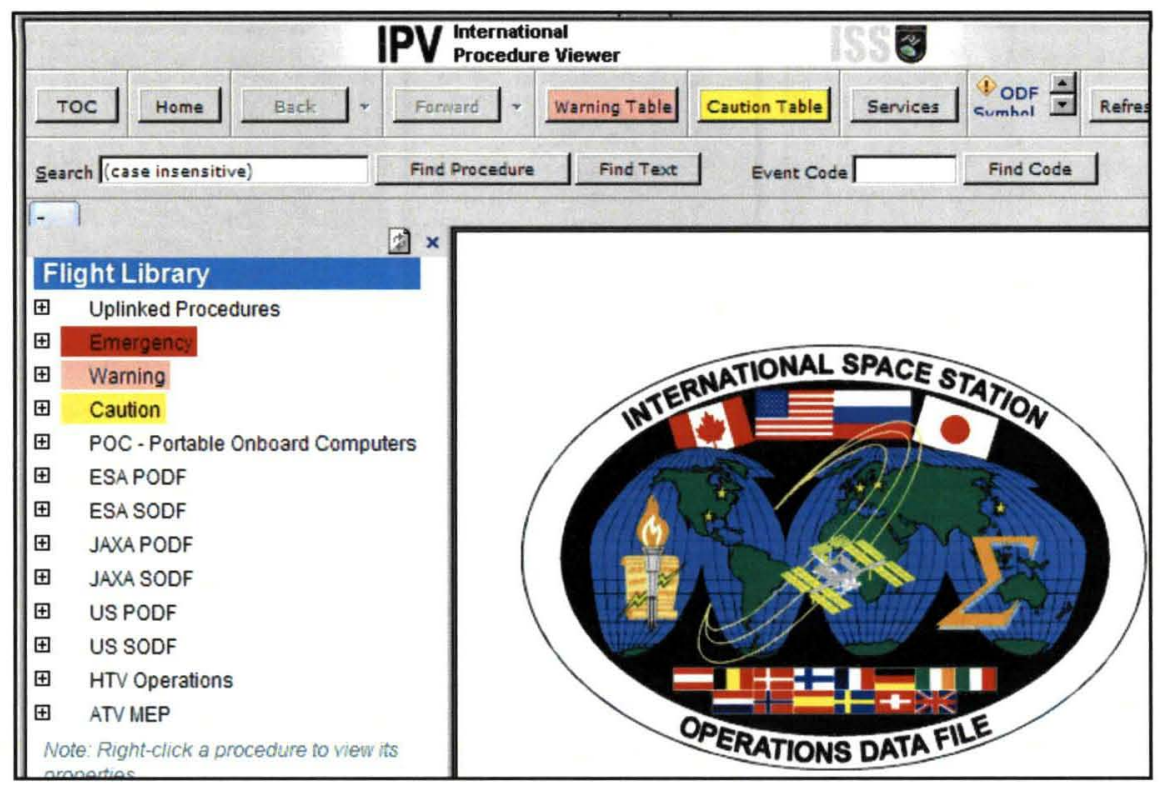

Figure 6. ISS International Procedure Viewer (IPV)

The IPV is used by the IP space agencies for the U.S., Japan, Canada, and Europe. Russia is the only IP not fully utilizing the IPV, but some IPV procedures are available in both Russian and English. The IPV uses XML structured authoring and a USA-developed XML viewer, similar to an industry IETM/IETP. The procedures use an XML schema based on NASA customizations agreed with the IPs, called Operations Data File (ODF). The schema produces a standard format defined by the ODF. Procedures use a "parameters" filtering feature, similar to S1000D's applicability, where the user selects the configuration, which customizes the given procedure. User data entry is collected and stored in a database, visible by astronauts and ground controllers simultaneously.

The European Space Agency (ESA) upgraded their IPV further by integrating it with onboard command and control software. This allows astronauts to execute a step in an IPV procedure, which then activates an onboard command during mission operations. S1000D has the capability to do this as well.

The IPV is an advanced system based on a suite of tools which was custom-developed by the operator USA. It happened to take a similar path to the S1000D specification, using compatible methods and tools, providing many similar features. The IPV shows an example of how S1000D could produce such a tech pubs system based on international standards, used for flight and/or mission operations of any space station/habitat or manned space vehicle. Many developing space programs could benefit from this approach today.

\section{Related Suite of Global Standards}

Tech pubs standards have been the primary focus up to this point, but many references were made to interoperability with other systems. S1000D is only one of an entire suite of standards originated by the ASD, called the S-series specifications.

\section{A. More Global Standards for Ground Processing}

In addition to S1000D, AIA and ASD are also collaborating on the S-series integrated logistics specifications, including specifications for Logistics Support Analysis, Provisioning and Procurement, Maintenance Support Activity and finally transfer of field data back to the designer's table. The intended benefits for developing these specifications are providing industry OEMs and government users a higher degree of data interoperability, achieving effective data exchange and feedback information transfers that can be used to understand and improve system performance and affordability. Hence, the OEMs will be more effective in assessing reliability and performance trends and improving mission assurance. We see that there are multiple opportunities for Materiel Readiness, Systems Engineering and Mission Assurance requirements to be embedded in the specifications. This endeavor complements the work on S1000D that has been ongoing between AIA, ASD, and ATA. 
The suite of 'S' standards provides an Integrated Logistics Support (ILS) package to the advantage of the product lifecycle manager. S1000D is constructed to provide logistics traceability for technical data throughout the hierarchy of the physical and/or functional architecture of the equipment. Harmonization and data exchange mechanisms between the standards supports communication and concepts of operations utilizing ERP, supply, operations and maintenance planning, and feedback systems for optimizing performance, affordability, and safety.

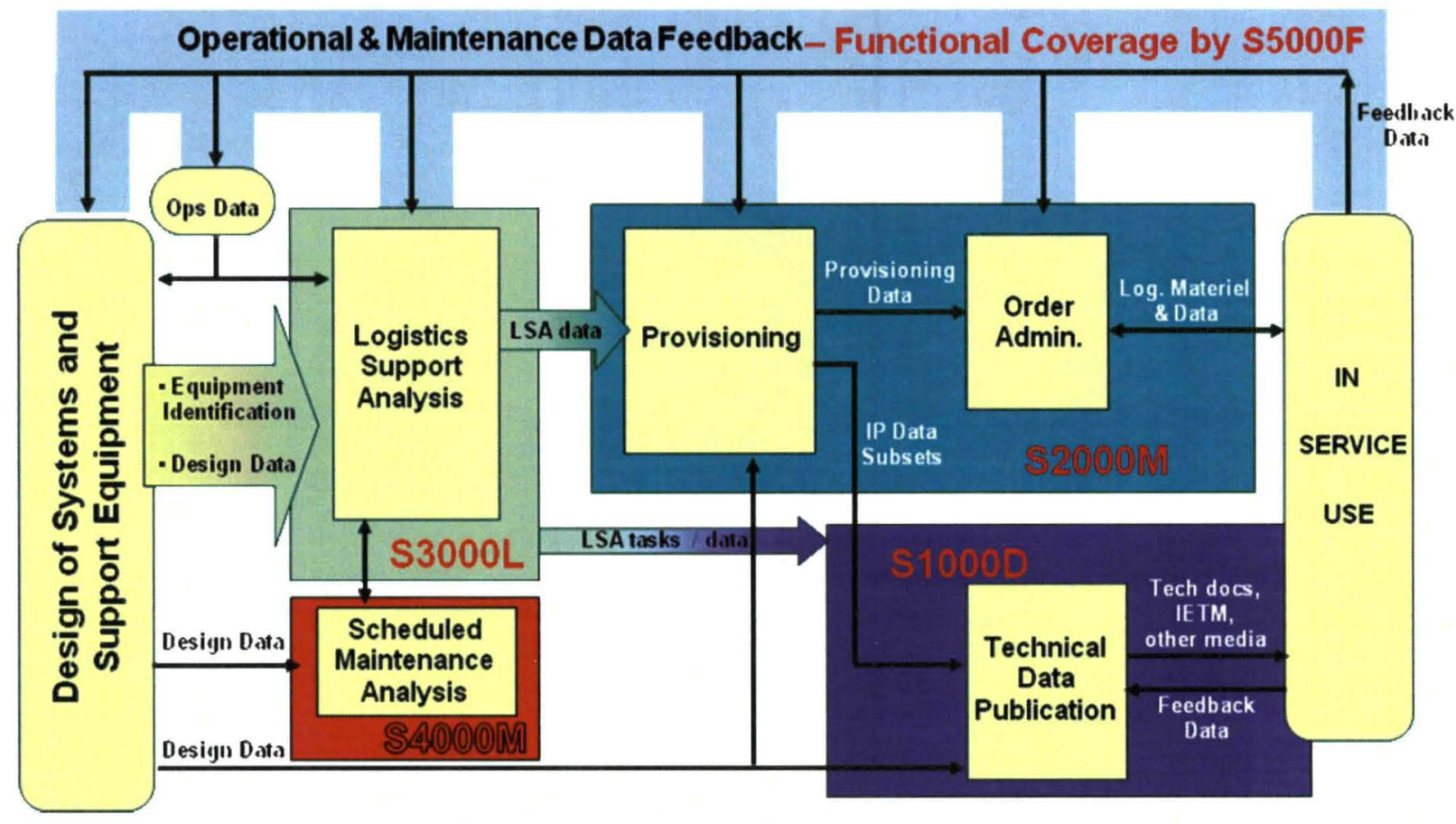

Figure 7. International S-series Specifications Are Designed for Interoperability

ILS, more recently called Integrated Product Support (IPS), is a common industry strategy which addresses a large portion of what the space industry calls ground processing. The individual functions of ILS are optimized for efficiency and supportability when properly interacting with one another. ${ }^{5}$ The figure above shows this interaction, with the S-series specifications labeled where applicable. See the descriptions below of each S-series specification and comparable industry standards:

S1000D: International Specification for Technical Publications Utilizing a Common Source Database $(\mathrm{CSDB})^{10}$

- Includes creation and management of Interactive Electronic Technical Manuals/Publications (IETM/IETP) like maintenance manuals, IPCs, fault isolation manuals, etc.

- Compare ATA iSpec2200: Information Standards for Aviation Maintenance (was ATA Spec100)

- Compare MIL-STD-1808: DoD standard for ATA-like numbering scheme (See ref. in S1000D.)

- Compare MIL-STD-38784: Technical Manuals, General Style and Format Requirements

- Compare MIL-DTL-87268: IETM, General content, style, format, \& user interaction requirements

S2000M: International Specification for Materiel Management ${ }^{11}$

- Includes provisioning, spares, etc.

- Compare ATA Spec 2000: E-Business Specification for Materiel Management

S3000L: International Procedure Specification for Logistic Support Analysis (LSA) ${ }^{12}$

- Includes LSAR database and other LSA aspects.

- Compare MIL-HDBK-502: Acquisition Logistics, DOD Handbook

- Old: MIL-STD-1388-1 Logistics Support Analysis (LSA) — cancelled, 1997

- Compare GEIA-STD-0007: Logistics Product Data (-XML-based, replaced MIL standards in 2008)

- Old: MIL-PRF-49506: Logistics Management Information (LMI) - cancelled, 2011

- Old: MIL-STD-1388-2 Logistics Support Analysis Record (LSAR) —cancelled , 1996

- Compare Def Stan 00-600: Integrated Logistic Support Requirements for MOD Projects (UK) 
S4000M: International Procedural Handbook for Developing Scheduled Maintenance Programs ${ }^{13}$

- (- will release in 2011)

- Includes scheduled maintenance analyses, RCM, etc.

- Compare ATA MSG-3: Operator/Manufacturer Scheduled Maintenance Development

S5000F: International Application Handbook for Operational and Maintenance Data Feedback

- (- in development, planned release in 2012)

- Includes interfaces with all other S-series specifications and other ILS/IPS elements, passing feedback for optimization.

Two other standards are also working hand-in-hand with the S1000D specification:

ASD STE 100: Simplified Technical English, International Specification for the Preparation of Maintenance Documentation in a Controlled Language. ${ }^{14}$

- This document originated from the growing need for clear communication of complex maintenance data.

SCORM: Shareable Content Object Reference Model ${ }^{15}$

- A standard for web-based e-learning. SCORM-compatible training publications can be produced using S1000D.

One key, common thread which enables interoperability between each specification is the hardware/system product breakdown structure. Structures are typically developed independently, and they can be mapped together, but they should be synchronized for maximum interoperable efficiency. The S-series product structures are:

SNS: for S1000D, Technical Publications

- ATA uses a standard system/subsystem breakdown (commercial aircraft only)

CSN: for S2000M, Provisioning / Material Management

- Catalog Sequence Number (CSN) for Illustrated Parts Data (IPD)

- MIL-STD-1388 uses a CSN

LCN: for S3000L, Logistics Support Analysis/Record (LSA/LSAR)

- LSAR Control Number (LCN) is typically developed during design

- MIL-STD-1388 \& GEIA-STD-0007 use an LCN

Family Tree Breakdown: for S4000M, Scheduled Maintenance Analysis (SMA)

- Includes Reliability-Centered Maintenance (RCM)

- MSG-3 is the ATA specification

\section{B. Convergence of ILS/IPS Standards/Specifications Toward Interoperability}

How does one know that these standards are proven and worth adopting? In addition to a growing set of global users, there is a history to their development.

The Computer Aided Logistics Support (CALS) initiative was begun by the U.S. Defense Department in 1985. Later, NATO also took up CALS. Its purpose is and was to facilitate the integration of digital information for weapons system acquisition, design, manufacture and support functions. CALS later changed to mean "Continuous Acquisition Lifecycle Support." An LSAR (Logistics Support Analysis Record) database standard MIL-STD-1388-2 was formed in relation to CALS, which the FAA also adopted. CALS required the OEM to create LSAR data and to include it with Interactive Electronic Technical Manual (IETMs), Support Equipment Recommendation Data, and Training Data. IETMs were based on MIL-M-87268 and MIL-D-87269, with SGML text authoring and CCITT Group 4 and CGM graphics standards.

Meanwhile, in Europe, the AECMA aerospace organization developed their own related standards, 1000D for IETMs, and 2000M for Illustrated Parts Catalogs (IPC) and Provisioning. The NATO CALS model was based on 3 standards: MIL-STD-1388-2B, 1000D, and 2000M.

AECMA has since been renamed ASD (AeroSpace and Defence Industries Association of Europe), and the two specifications are called S1000D and S2000M. The U.K. has since developed DEFSTAN 00-600 for ILS, GEIA's LSA standard GEIA-STD-0007 replaced military standards, and ASD has just developed S3000L for LSA. These standards have been transitioning their data exchange standard from SGML to XML, the latest trend. 


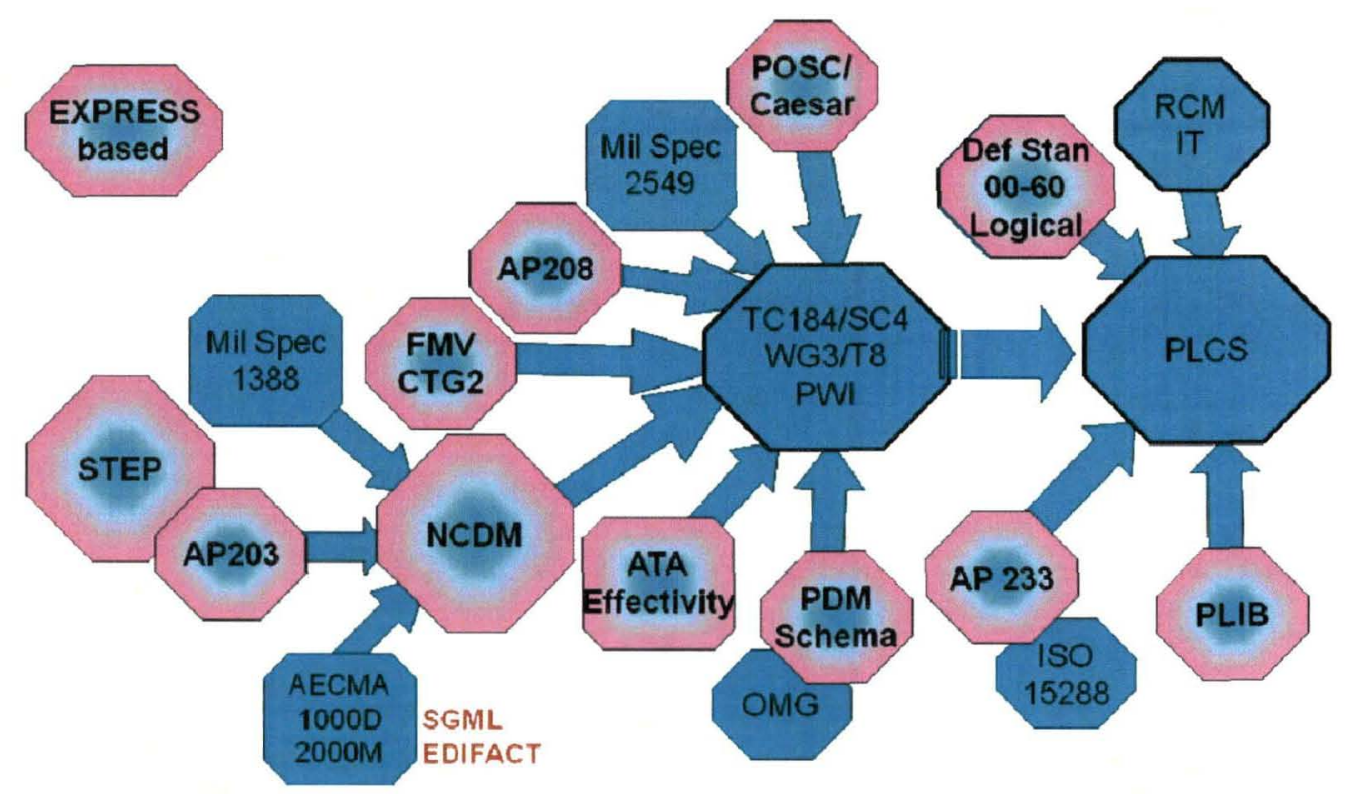

Figure 8. PLCS Relationships to Standards and Programs during Development 1999-2004 ${ }^{16}$

\section{Integrating ILS Standards for the Life Cycle}

To integrate all of these ILS functions/specifications, the S-series committees have worked toward compatibility with ISO standard 10303: STandard for the Exchange of Product model data (STEP). As seen in the figure above, this very broad standard has many integrated Application Protocol (AP) "parts," which address specific products and processes. Almost every AP can be used by most industries and for most products.

AP 239 (10303-239) is Product Lifecycle Support (PLCS), which enables the creation and management through time of an assured set of product and support information, which can be used to specify and control required support activities throughout a complex product's life.

AP 239 addresses support of the system from concept to disposal. It enables you to: request, define, justify, approve, schedule and capture feedback on work activities/resources; document product requirements and configuration as-designed, as-built, and as-maintained; provide feedback on product properties, operating states, behavior and usage; and define support opportunities, facilities, personnel, and organizations for the complete aircraft or spacecraft description of structural envelope, distributed systems, and the subsystems/equipment. ${ }^{17}$

PLCS can become the hub around which all S-series systems inteface, rather than making them interact individually with each other. It will maintain data flows, enabling optimum interoperability, thus lowering costs and reducing ground processing time. The space industry would do well to adopt this standard, too. ${ }^{5,18}$

\section{Space Industry Usage}

For the completed the S-series specifications, we already mentioned the few known cases where S1000D is used in the space industry. The authors do not know of any cases of S2000M or S3000L usage for space.

However, the equivalent predecessor to S3000L, MIL-STD-1388, has been used by many companies to produce an LSA/LSAR. Many do not even know that some of their technical data and decisions came from an LSAR. USA and Boeing manage an LSAR for the ISS, integrated with the IPs, like the IPV is. The potential exists for programs such as the ISS to gain even more efficiency by taking advantage of the standard interfaces to connect an LSAR to an XML-based tech pubs system, especially if both systems are built on compatible standards. Also, many of NASAs Ares I-X requirements directed for LSA to be performed and LSARs to be built. This effort was begun until Constellation was cancelled. Other space programs/projects probably use one of the LSA/LSAR standards, though not known to the authors.

NASA is in the process of developing an ILS handbook which is looking at specifications like S3000L and GEIA-STD-0007 for an LSA/LSAR, amongst other ILS aspects.

PLCS is a significant topic in all industries. NASA and the ESA have been working efforts for a number of years to utilize the ISO 10303 STEP standard, including PLCS. They have had annual workshops for collaboration. USA 
partially implemented a PLCS system during Ares I-X test rocket assembly and launch operations, with a goal to continue working toward a full PLCS for future space programs.

\section{Conclusion}

The space industry is not immune to the same information management issues in other industries. In fact, in many cases, it might be harder to find the right information in a timely manner due to lack of common knowledge, designs, methods, and tools. In the same way, the space industry is able to utilize many of the same solutions available to other industries, as applicable to ground processing, or ILS/IPS. Many best practices have been captured and put into standards and specifications, and many COTS software tools have been created to match.

Ground processing of any launch vehicles, spacecraft, facilities, space stations/habitats, etc. could benefit from industry standards, even those not customized for space. Some can even apply to aspects of flight and mission operations. Let those developing standards for space hardware design continue with those important efforts. Ground support in an ILS/IPS realm does not need as much specialization to gain efficiencies, but can utilize industry standards for known applicability.

The SMM project is one example where an industry standard was attempted on Shuttle and showed promise. The ISS is using a standard with international integration. Ares I-X has shown some efforts toward using standards. NASA and the ESA are working toward PLCS and other STEP standards. EELV recognized the need for standard hardware and processes and has taken steps to improve. The space industry needs to turn-up the efforts toward standards even more. It also needs to step back and look at the big, integrated picture, to strategize for optimal application of standards.

The global space community must work together to successfully grow the viability of the space industry. All members, commercial, civil, and government, will need to engage cooperatively in developing and applying standards to move toward interoperability. If we leverage and combine the best existing space standards and specifications, develop new ones to address known gaps, and adopt the best applicable standards from other industries, we can establish an infrastructure to not only accelerate current development, but also build longevity for a more cohesive international space community.

\section{Acknowledgments}

The authors thank the following people who contributed to the success of this paper:

- Dan Ciccateri, Deputy Director, Launch \& Recovery Services Engineering, United Space Alliance

- Joe Jacoby, Industrial Engineer, United Space Alliance

- Katrine Stelges, Industrial Engineer, United Space Alliance

- Jan Haslam, Secretary of the S1000D Steering Committee

- Paul Haslam, S1000D Consulting, Ten On Eleven, Inc.

- Louis Iuppa, Vice President, Business Development, SDL Structured Content Technologies Division

- Rusty Rentsch, Assistant Vice President, Technical Operations, Aerospace Industries Association (AIA)

\section{References}

1. Spira, J., "Overload 101", April 28, 2011, Overload Stories [online source, cited 9-9-2011]. URL: http://www.overloadstories.com/2011/04/overload-101/.

2. Houlihan, D., "Securing the Value of Content Reuse: Why 'More Content' Means Less than 'How Easily", Aberdeen Group, June 30, 2010, The Dynamic Publisher (online articles). URL: http://www.thedynamicpublisher.com/category/Technical-Publishing.aspx . [Cited 9-9-2011]

3. Air Force Space Command Document (AFSPC 003-93-I I). Operational Requirements Document (ORD) II For The Evolved Expendable Launch Vehicle (EELV) System, 15 September 1998. URL: http://www.globalsecurity.org/space/library/report/1998/eelv-ord.htm .

4. "Range Standardization and Automation (RSA)", FY00 Annual Report, Director, Operational Test and Evaluation, Office of the Secretary of Defense. URL: http://www.dote.osd.mil/pub/reports/FY2000/airforce/00rsa.html [online source, cited 9-9-2011]. 
5. Ingalls, J., "Ground Processing Affordability for Space Vehicles", Sep. 2011, AIAA Space 2011 Conference and Exposition, Long Beach, California, (submitted for publication).

6. "The Hidden Costs of Information Work", a 2006 IDC (International Data Corporation) study of information/knowledge workers in financial services, government, manufacturing and healthcare organizations in the U.S. is quoted in numerous articles, including those listed here and used for this paper. URLs: Used citations at http://h41320.www4.hp.com/ipge/pdf/Spotlight on costs_3.pdf $\quad, \quad \underline{\text { http://msdn.microsoft.com/en- }}$ us/library/bb887531.aspx , http://www.tribridge.com/Libraries/White_Papers/WP-EnterpriseSearchMicrosoft.sflb.ashx , and http://www.opentext.com/2/global/press-release-details.html?id=2203 [cited Sep. 6, 2011].

7. Houlihan, D., "Technical Communications as a Profit Center", a Sep. 2009 study by the Aberdeen Group. URL: http://www.ptc.com/WCMS/files/102942/en/6017-RA-TCProfitCenter-DH-11-NSP.pdf .

8. Ericsson, S., "S1000D - A Tutorial", 21 Oct, 2008, presentation at 2008 Joint ATA e-Business Forum and S1000D User Forum, Budapest, Hungary. URL: http://www.ataebiz.org/forum/2008 ata e-biz forum agenda .

9. Duffy, K., "XML-based Content Management - Control is King”, May/June 2007, AIIM E-Doc Magazine, Association for Information and Image Management (AIIM). URL: http://www.aiim.org/Resources/Archive/Magazine/2007-MayJun/33460 . [Online magazine, cited 9-9-2011].

10. S1000D: Int'1 Specification for Technical Publications Utilizing a Common Source Database, ASD, AIA, and ATA. URL: http://www.s1000d.org .

11. S2000M: Int'l Specification for Materiel Management, ASD. URL: $\underline{\text { http://www.asd- }}$ stan.org/standards/Qstandards.asp? RecNo=20008.

12. S3000L: Int'l Procedure Specification for Logistic Support Analysis (LSA), ASD. URL: http://www.asdstan.org/s3000L.html .

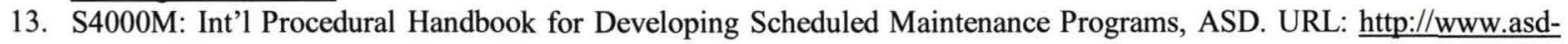
stan.org/S4000M_000-01_distr.pdf (to be published).

14. ASD-STE100: Simplified Technical English, International Specification for the Preparation of Maintenance Documentation in a Controlled Language, ASD. URL: http://www.asd-ste100.org .

15. Sharable Content Object Reference Model (SCORM), Advanced Distributed Learning (ADL). URL: http://www.adlnet.gov/capabilities/scorm .

16. Mason, H., "Product Life Cycle Support (PLCS) The Information Backbone to transform the Logistics Enterprise", presentation at Transatlantic PLCS/10303 meeting, for U.S. DoD UID Program Office, Feb. 16, 2006. URL: http://www.acq.osd.mil/dpap/pdi/uid/iso_10303_step_ap_239 plcs.html .

17. Product Life Cycle Support (PLCS) Resources, website sponsored by Eurostep for ISO standard 10303-239. URL: http://www.plcs-resources.org/ [cited Sep. 6, 2011].

18. Ingalls, J., "S1000D and Beyond for Space", May 2011, presentation at Aerospace Industries Association (AIA) / Joint Services Technical Publications Workshop, Clearwater, FL, p. 33. URL: https://acc.dau.mil/CommunityBrowser.aspx?id=452827\&lang=en-US . 


\title{
Standards and Specifications for Ground Processing of Space Vehicles: from an Aviation-based Shuttle Project to Global Application
}

\author{
John Ingalls \\ Sep. 27-29, 2011 \\ AIAA Space 2011 Conference \& Exposition \\ * United Space Alliance
}




\section{About the-Authors}

- John Ingalls, United Space Alliance, LLC (USA)

- Senior Engineer, Launch \& Recovery Systems

- S1000D, USSMG (U.S. Specification Maintenance Group)

- International Specification for Technical Publications

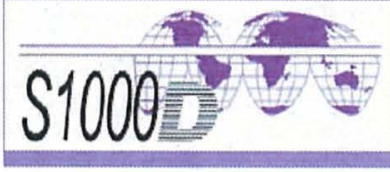

- AIA's SSFA (Strategic Standardization Forum for Aerospace)

- AIAA Senior Member

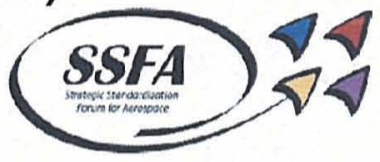

- John Cipolletti, United Space Alliance, LLC (USA)

- Director, Aerospace Services Engineering

- Chief Engineer, Space Shuttle Ground Operations

- AIAA Senior Member

- About USA

- Joint venture, Boeing and Lockheed-Martin

- Numerous space industry services and products

- John \& "Cip" are from the Florida division at NASA KSC

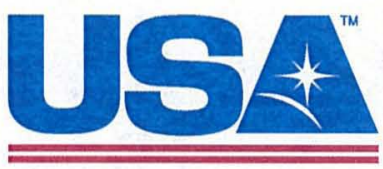

United Space Alliance 


\section{Outline}

- Introduction

- Need for Standardization in the Space Industry

- Shuttle Maintenance Manual (SMM) Project

- Optimization of Technical Publications for Space

- Related Suite of Global Standards

- Conclusion

- Questions 


\section{Introduction}

- Space Industry Conditions

- Economy and commercialization driving need for efficiencies

- Space Industry Technical Data Needs Efficiencies

- High quantity \& complexity of data

- Even has unusual types: kitchen, scuba, rocks, pool, sleep schedules, etc.

- Studies on Information/Data Usage in Various Industries Revealed:

- Technical data reuse initiatives increase efficiency, but also complexity

- Time spent:

- $48 \%$ - searching ( $9.5 \mathrm{hrs} / \mathrm{wk})$ \& analyzing ( $9.6 \mathrm{hrs} / \mathrm{wk})$ information

- $3.5 \mathrm{hrs} / \mathrm{wk}$ - in unproductive searches (info not found)

- $3 \mathrm{hrs} / \mathrm{wk}$ - recreating content that already exists

- A minimum of 28 billion hours is lost each year to "Information Overload" for information/knowledge workers in U. S.

- Need Plan for Structure and Efficiency

- Electronic does not necessarily mean efficient

- Information structures and their data systems must be well-organized 


\section{Need for Standarelization-in Space lnd dustriry}

- Standardization

- Provides structure

- Normalizes and optimizes

- Increases efficiency

- Industry Standards for Space ${ }^{\text {OST }}$

- Various organizations

- Most standards focus on design, not ground

- Space Ground Processing

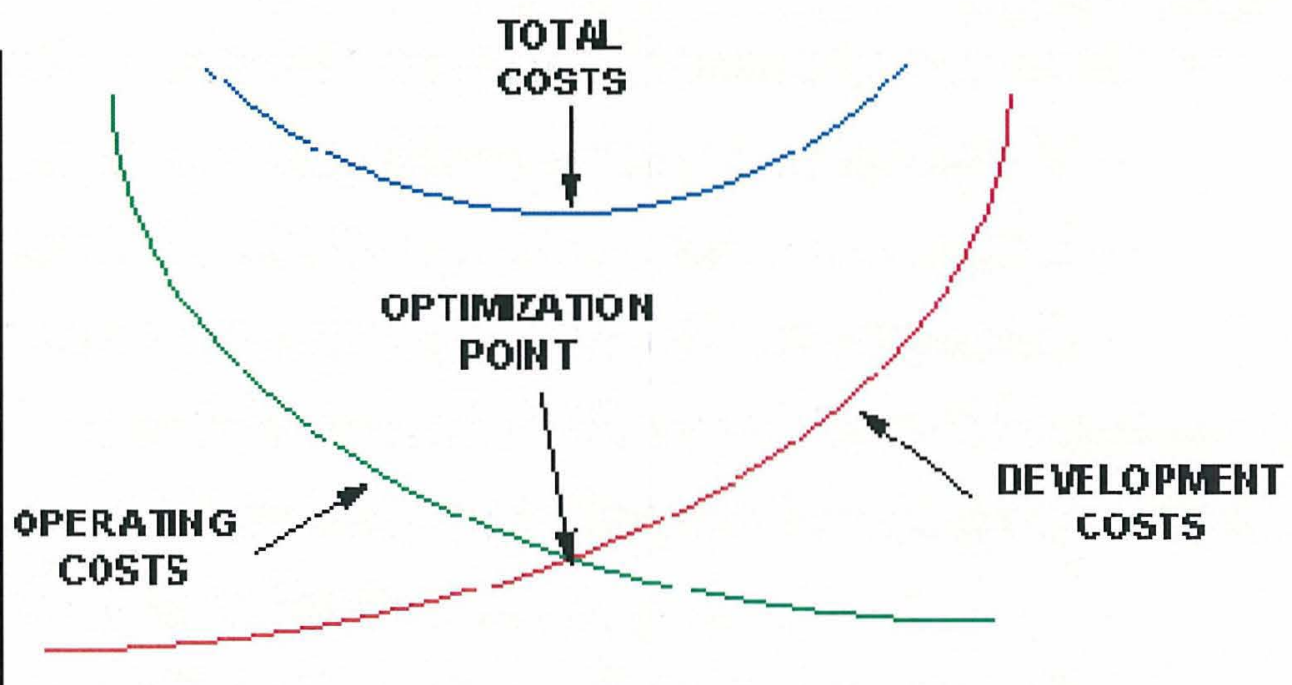

AMOUNT OF STANDARDIZATION

Example of Estimated Standardization Effects

\section{Needs Standards}

- Operating \& support costs are $60-80 \%$ of total lifecycle costs (LCC)

- Includes from assembly operations to launch

- For RLVs, also includes recovery/landing, post-flight , \& MRO 


\section{Shuttle Maintenance-Mantall (SMIM) Projech}

- Ground Maintenance of NASA's Shuttles

- Varying technical publications \& data

- Engineers required on $80 \%$ of issues

- Exception: Orbiter thermal protection

- Aviation-Based Efficiency Efforts

- Structural Repair Manual (SRM) idea

- Make like ATA industry standard

- Re-scoped intent to full Shuttle as:

- Shuttle Maintenance Manual (SMM)

- Improvement objectives

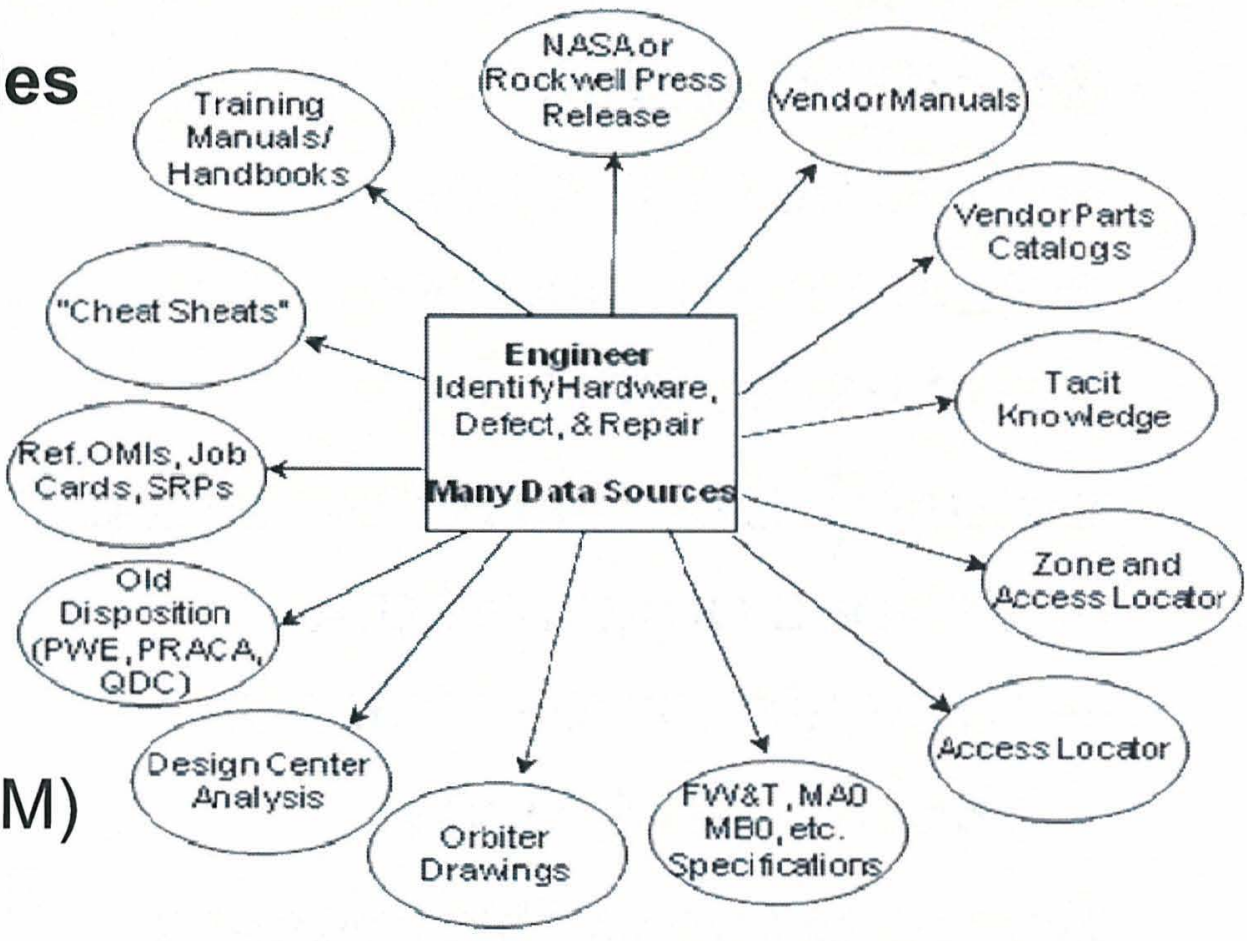

- Reorganize procedures \& technical data together as "tech pubs"

- Combine all document types \& formats into one

- Web-based access, include multimedia, separate verify sheets

- Numbering scheme was a key, using hardware-based product structure

- SMM Pilot Program Initiated

- Metrics needed to validate concept

- Limited to Orbiter Aft Fuselage, horizontal shop, maintenance subtasks 


\section{Shuttle Maintenance-Manual (SMM) P) Pojeç}

- Pilot Program Results

- Pre-SMM data (legacy)

- SMM Pilot data

- Limited data collection still validated concepts

- Reduced times

- Give more to shop

- Current Project Status

- Conditions changed

- SMM benefits produced

- Improvements since pilot

- More systems, data

- More data types

- Unique IT structure

- Model for future programs
Pre-SMM Data

Percent Time by Activity

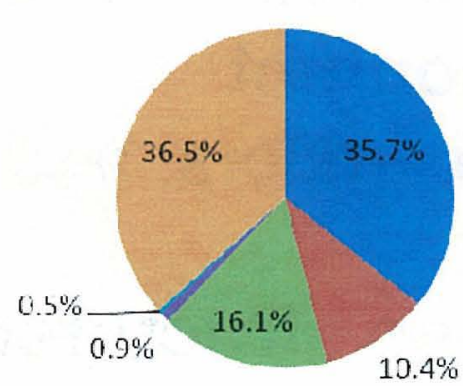

- Identify Problem

Eesearch / Evaluate

Disposition

Document Assembly

- Scheduling

- Hardware Hancs-on Work

SMM Pilot Data

\begin{tabular}{|l} 
Shutte Maintenance ManUal (SMM) \\
a comprehensive technical reference system
\end{tabular}

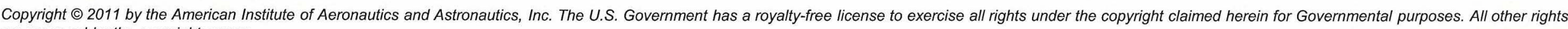
are reserved by the copyright owner 


\section{Optimization-of -Fechnical-Publications}

- Like SMM, "Tech Pubs" Optimization Is Significant in Industry

- A Study of Technical Communications, Best-in-Class Statistics:

$-65 \%$ increase reuse of content

- $100 \%$ use graphic/image editors, and $43 \%$ use rich media / e-learning editors

$-46 \%$ more likely to leverage structured authoring editors

- $86 \%$ more likely to use CMS [Content Management System] to manage relationships between content components

- Best were $38 \%$ and $61 \%$ more likely than industry average performers and laggard performers, respectively, to automatically assemble content based on product configuration

- S1000D Does These-the Next Generation in Tech Pubs

- 1985 European specification now global, via ASD, AIA, \& ATA

- Examples of industry use:

- Boeing 787, Global Hawk, AMRAAM missile, CH148 Cyclone helicopter, EMALS/AAG systems on CVN78 ship 


\section{Optimization-of Technical-Publications}

- S1000D Powerful Features

- Based on International Standards (W3C, ATA, ISO)

- Electronic Publications (IETM/IETP)

- Standard Numbering System (SNS) Product Breakdown Structure

- Modularity for Reusability / Repurposing

- Common Source Database (CSDB)

- Illustrations, Multimedia, and CAD

- Applicability-Structured Configuration Varieties

- Business Rules Exchange (BREX)

- External Interoperability

- S1000D Other Benefits

- Improves configuration management, safety, quality

- S1000D Uses XML Data Exchange Standard

- ROI (return on investment) is well-proven for XML utilization

$-\mathrm{XML}$ industry standard has many other applications 


\section{Optimization-of-Technical-Pulblications}

- Case Study: Benefits of S1000D for a U.S. Military Customer

- Decreased lifecycle support costs, increased quality

- ROI factors: $70 \%$ reuse, $50 \%$ manual production cost, etc.

- Other benefits: Applicability, consistency (risk reduction), etc.

- S1000D Applicability to All Space Products

- Designed for air, land \& sea vehicles \& equipment.

- Add Space: Launch vehicle, payload, spacecraft, space station/habitat, facility, lunar lander, \& recovery ship

- S1000D known space usage

- (U.S.) DoD SpaceLift Range System (SLRS), (Germany) DLR's Galileo satellite ground station, (Italy) ESO's space telescope

- S1000D Working Group involvement

- Ideal for new projects, ROI on some conversions

- First step: Establish product breakdown structure 


\section{Optimization-of-Technical-Publicakions}

- International Space Station's (ISS) Similar IETM for Astronauts

- Tech pubs used to operate, maintain, and resupply

- IETM used is IPV (International Procedures Viewer)

- Similarities to S1000D

- XML authoring, viewer

- ODF (Operations Data File

- Parameters (Applicability)

- Used by Int'I Partners (IP)

- ESA upgrade - flight software

- USA-developed suite of tools

- IPV Shows S1000D Potential

- Potential flight/mission

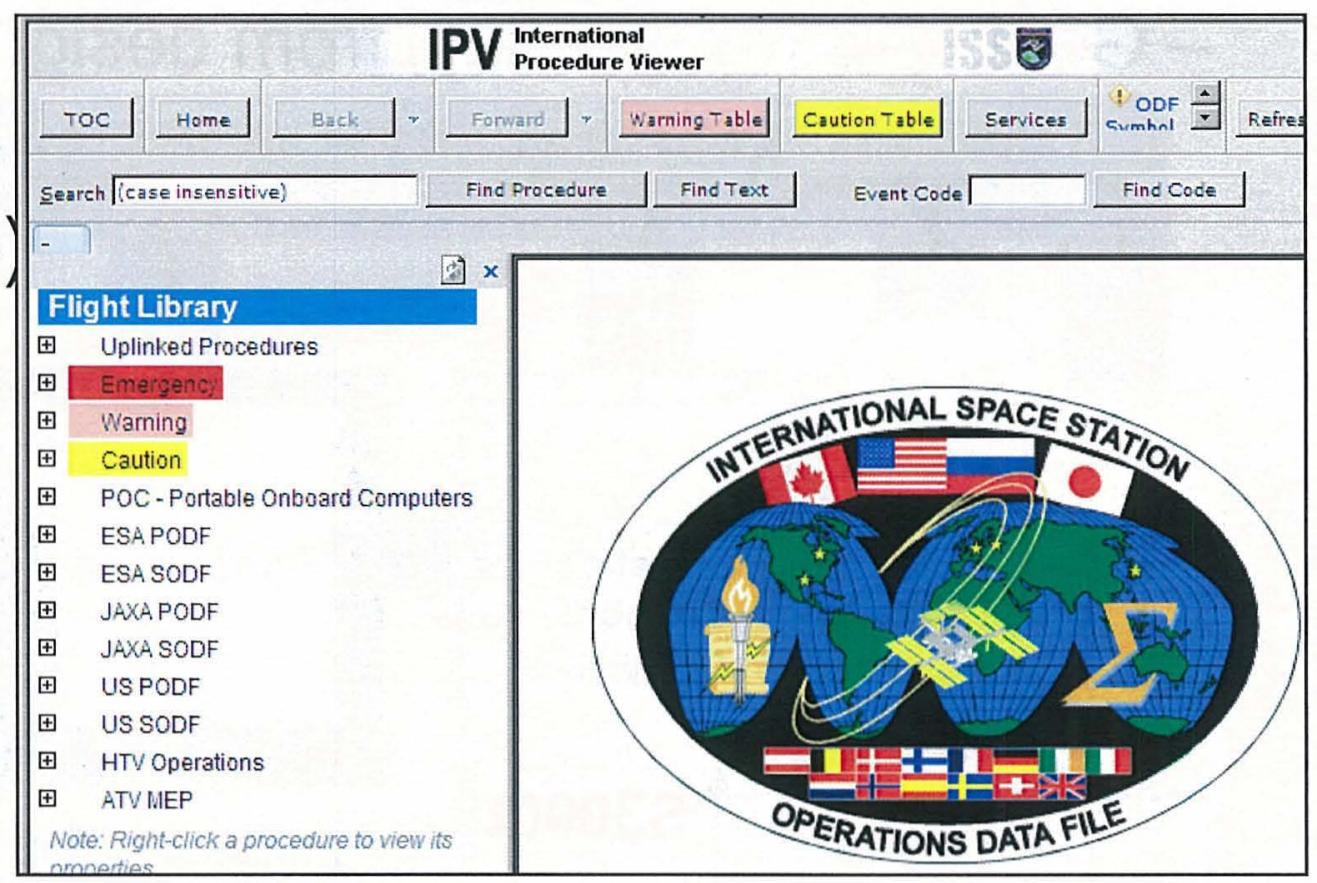
operations use

- Manned space vehicles or space stations/habitats 


\section{Related Stite-of-Global-Standards}

- S-series Specifications (Companions to S1000D)

- Jointly managed by Europe's ASD \& America's AIA

- ILS (Integrated Logistics Support)/IPS (Integrated Product Support)

- Goal: interoperability, from design through support lifecycle

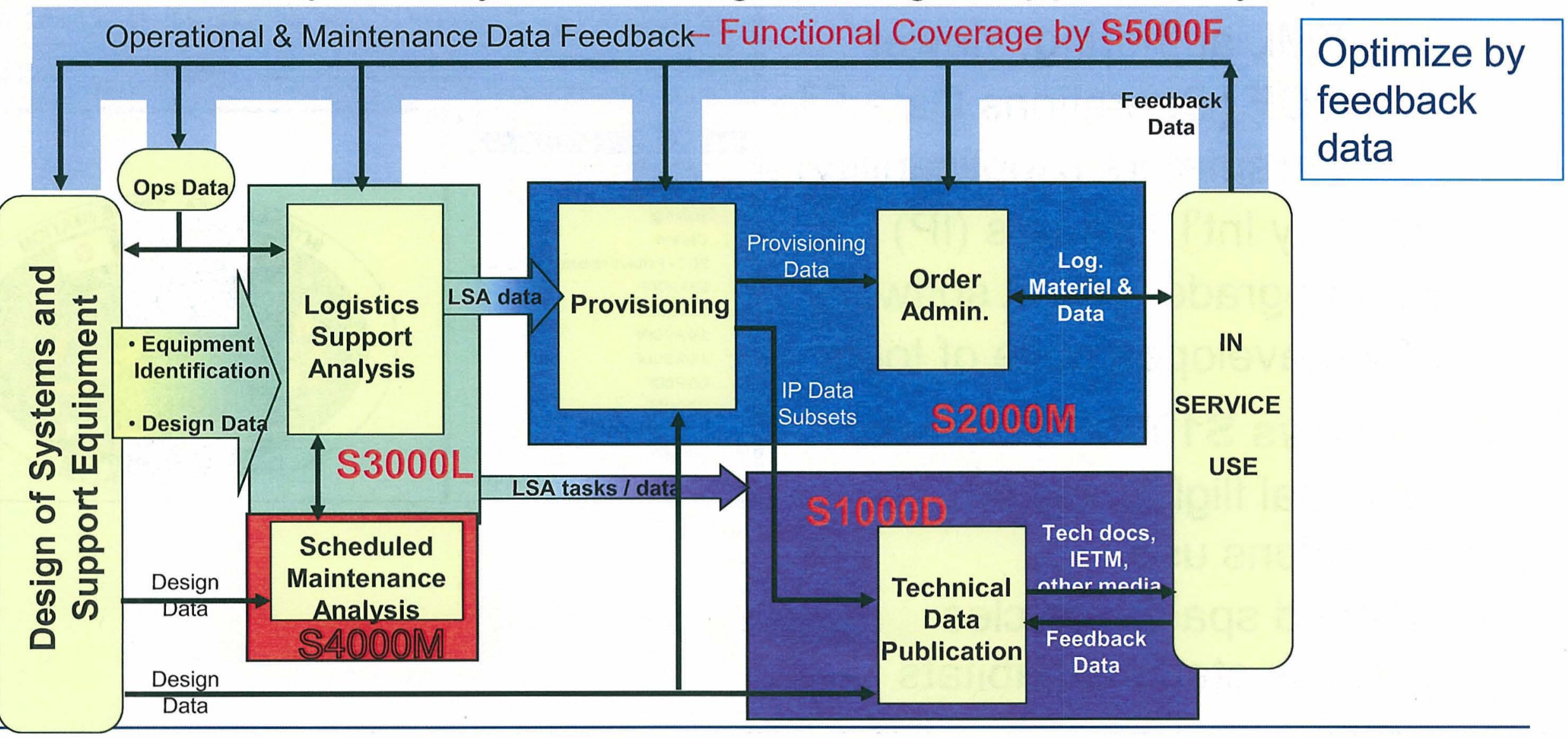




\section{Related Stite-of-Global-Staindards}

\section{- S-series Specifications}

S1000) International Specification for Technical Publications

International Specification for Materiel Management

S3000 International Procedure Specification for Logistic Support Analysis (LSA)

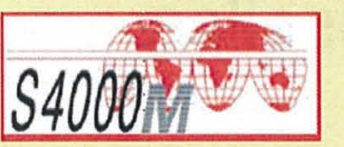

International Procedural Handbook for Developing Scheduled

Maintenance Programs (-scheduled to release in 2011)

S5000?

International Application Handbook for Operational and Maintenance

Data Feedback (-developing to release in 2012)

\section{- Companion Standards to S1000D}

ASD-STETOO

S SIMPLIFIED mangtst

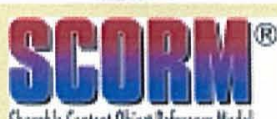

ASD STE 100: Simplified Technical English, International Specification SCORM (Shareable Content Object Reference Model), a standard for web-based e-learning 


\section{Related Stite-of-Elobal-Standards}

- Product Breakdown Structure - A Common Link

- Hierarchical hardware/system layout

- Physical, functional, or hybrid

- Can drill-down to lowest component

- Represented by intelligent numbering / letters

- S1000D calls this SNS (Standard Numbering System)

- Preset for air, land, \& sea vehicles \& equipment, \& missiles

- Air SNS is from ATA specifications

- Unique allowed, but preset SNS is most efficient

- S2000M calls this CSN (Catalog Sequence Number)

- S3000L calls this LCN (LSAR Control Number)

- S4000M uses SNS from S1000D 


\section{Related Stite-of-Global-Standards}

- SNS Structure in the S1000D Data Module Code (DMC)

- Variable Character Length: min. 17 to max. 41 (gray $X$ is optional)

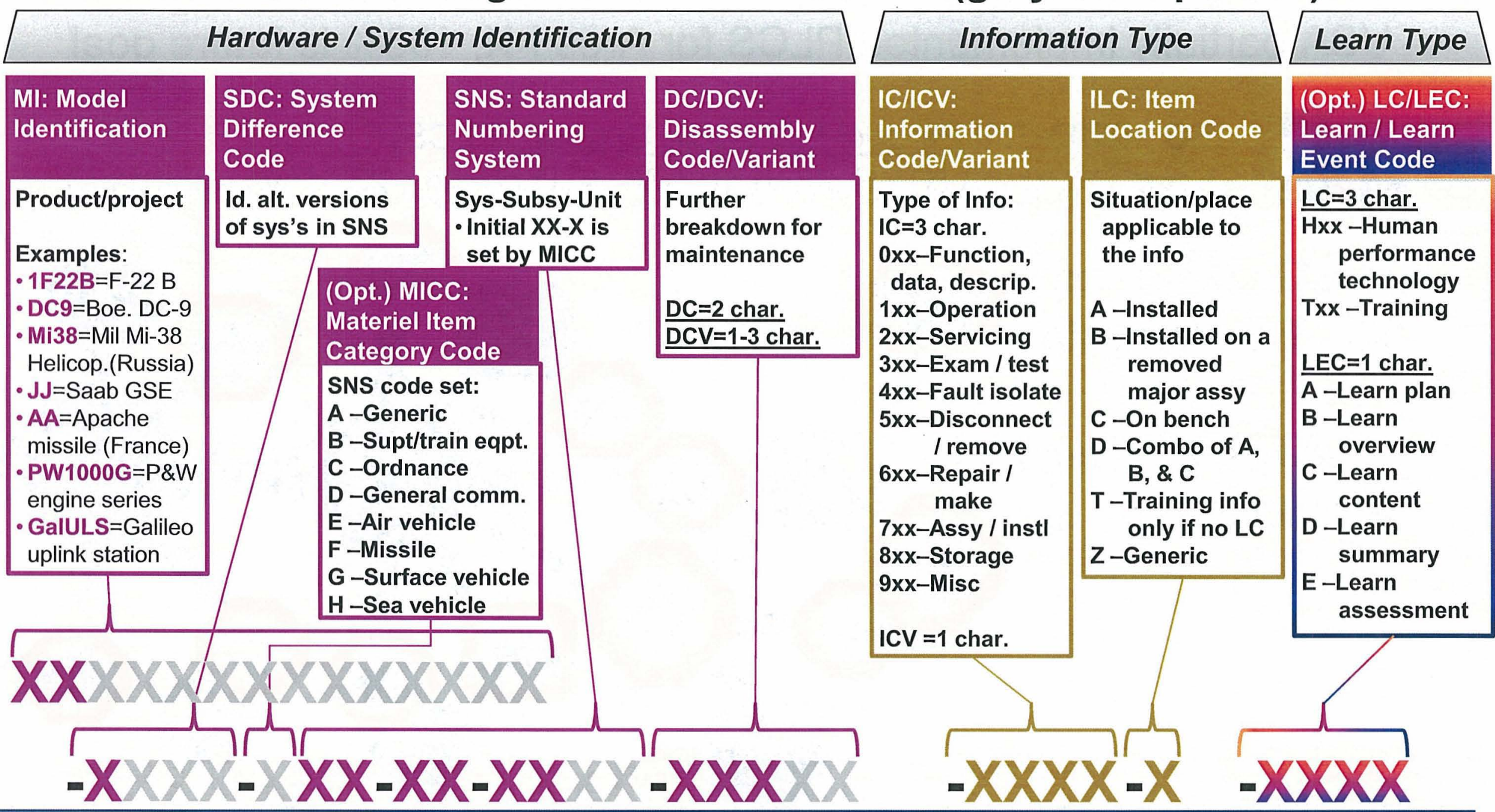




\section{Related Suite-of-Global-Standalpds}

- Convergence of ILS/IPS Standards Toward Interoperability

- Joint NASA and ESA efforts to ISO 10303 STEP standard

- USA partially implemented PLCS for Ares I-X; $100 \%$ is future goal

PLCS

ISO 10303-239 Product Life Cycle Support (PLCS)

- part of 10303 STEP standard (-203=3D config, $-233=$ Sys engr data)

- PLCS addresses ILS/IPS elements

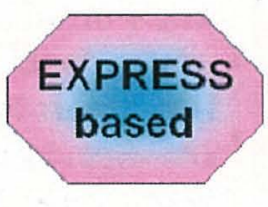

- S-series are designed around PLCS

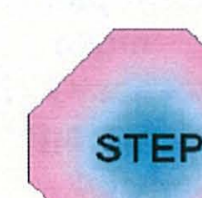




\section{Integrating-HSStandards for the Lifecyele}

- Optimal Efficiencies with IT Integration to Enable Interoperability

- Recommend S-series Suite of Standards, with PLCS Standard

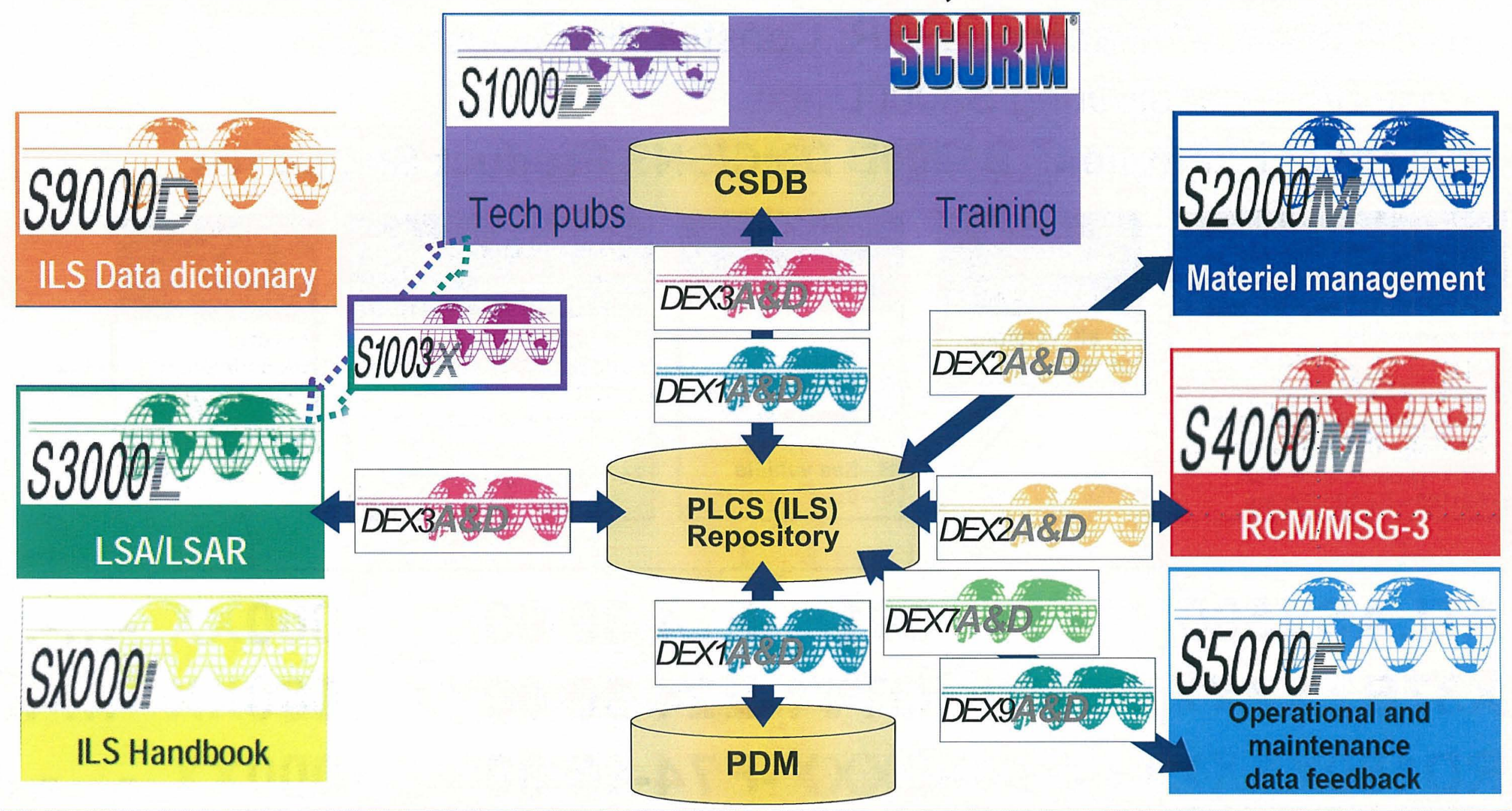




\section{Space Industiry Usage and - Op portunites}

- Any Space Product - Recommend S-series + PLCS

- Standard LSA/LSARs Can Interface with S1000D

- ISS has multi-national LSAR; Constellation began LSAs

- NASA is considering S3000L now

\section{- Potential Examples: S1000D DMC/SNS Product Structures}

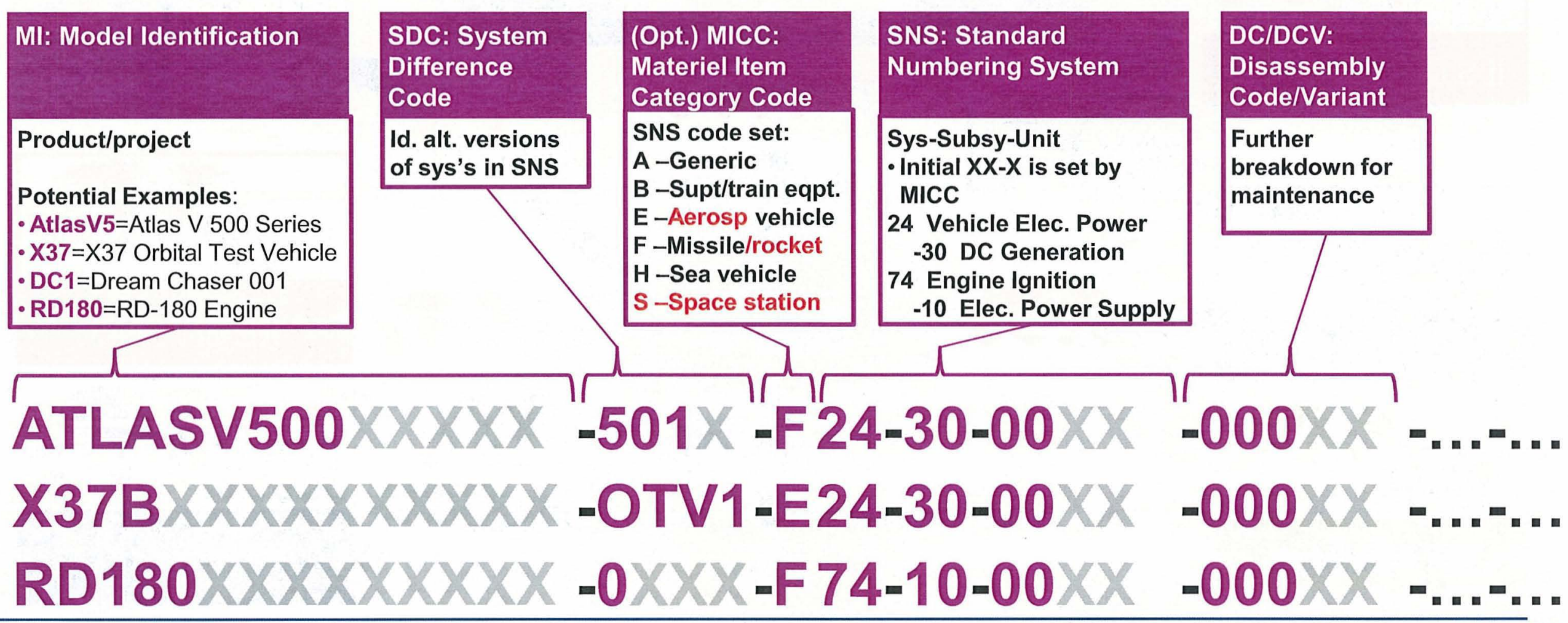




\section{Conclusion}

- Efficiency Requires Well-Organized Technical Data

- Shuttle Maintenance Manual (SMM) Pilot Indicates Value

- Non-Space Industry Standards Provide Optimized Solutions

- Ground processing and flight/mission operations can benefit

- Standard interfaces with design data are available

- S1000D for tech pubs: Emerging global standard; some space use

- S-Series global specifications provide ILS/IPS functionality

- PLCS standard integrates S-series for optimized interoperability

- Space Industry Opportunities

- Recommend to expand current ILS/IPS standards efforts

- Utilize S-series/PLCS for new and some existing space products

- Join working groups of standards organizations (S-series, PLCS)

\section{Streamlined Product Support Standards: Organize, Build Once, Reuse, \& Integrate}




\title{
Questions?
}

\section{"The heart of the prudent acquires knowledge, And the ear of the wise seeks knowledge."}

\author{
Proverb
}

QUESTIONS? 